\title{
Groei en productie van ruwe berk in Nederland
}

J.J. Jansen ${ }^{1}$, A. Oosterbaan ${ }^{2}$, G.M.J. Mohren ${ }^{1}$ en J. den Ouden ${ }^{1}$

FEM Groei en Productie Rapport 2018 - 13

\section{WAGENINGEN}

UNIVERSITY \& RESEARLH

\footnotetext{
1 Forest Ecology and Forest Management group, Wageningen University, Department of Environmental Sciences 2 Nature and Society, Wageningen Environmental Research (WENR)
} 
Jansen, J.J., A. Oosterbaan, G.M. Mohren en J. den Ouden, 2018. Groei en productie van ruwe berk in Nederland, FEM Groei en Productie Rapport 2018 - 13, 41 blz.

Synopsis: Van 1982 tot 1994 is in Nederland groei- en productieonderzoek bij de ruwe berk uitgevoerd. Dat betreft de studie van de Dorschkamp/IBN. Samen met de permanente steekproeven uit de HOSP zijn 43 proefperken met 132 opnamen beschikbaar.

Voor de ontwikkeling van de opperhoogte $h_{\text {top }}$ met de leeftijd $t$ werd het heteromorfe model van Cieszewski gekozen, met asymptoot en 3 andere parameters. Als site index is voor de $h_{50}$ gekozen. De diameter bij een hoogte van $7 \mathrm{~m}\left(d_{7}\right)$ geschat met zowel de data uit de $4{ }^{\mathrm{e}}$ Bosstatistiek als die van de proefperken, het gemiddelde is aangehouden. Voor de groei tot $d_{7}$ werd een powerfunctie gevonden. Met een powerfunctie werd de grondvlakbijgroei $i_{G}$ verklaard met $h_{50}, h_{\text {top }}, t$ en standruimte index van Hart $S \%$. Voor $S \%>19.5$ daalt de grondvlakbijgroei met een niet-lineaire functie in $S \%$. Het effect van de dunning op de diameter na dunning is gemodelleerd met het model van La Bastide \& Faber.

Er is een opbrengsttabel gemaakt met een sterke laagdunning en vijf boniteiten.

Abstract: In the Netherlands growth and yield research on silver birch was done from 1982 to 1994. This includes studies by the Dorschkamp/IBN research institute and by Wageningen University. Together with the permanent sample plots from the timber prognosis system HOSP, this comprises a dataset of 43 plots with 132 recordings. For the development of top height $h_{\text {top }}$ with age $t$ Cieszewski's polymorphic model with site index $h_{50}$ and three additional parameters fitted best. The diameter at a height of $7 \mathrm{~m}\left(d_{7}\right)$ was estimated with the plot data and with the data of the Fourth National Forest Inventory, and the average of both estimates was chosen. The diameter development up to stand height of $7 \mathrm{~m}$ was described with a model of Jansen et al., a power function in $h_{\text {top }}$ and the estimated value for $d_{7}$. From a stand height of $7 \mathrm{~m}$ upwards, the basal area increment $\left(i_{G}\right)$ was also described by Jansen's et al. model based on a power function with $h_{50}$, $t$, year of recording (yor), and the stand density of Hart ( $S \%)$. For $S \%>19.5$ the basal area increment decreases non-linear with increasing $S \%$. The model contains a correction factor for yor, although this was not significant, as the year of recording (yor), turned out to be not significant. The effect of thinning on the diameter after thinning was modelled with the La Bastide-Faber model.

The models were used to construct a yield table with five site classes and one thinning intensity.

Keywords: Silver birch, Betula pendula, Netherlands, yield table, thinning grade, Becking-Hart spacing index, height growth models, power model for basal area increment, La Bastide-Faber model for thinning effects.

Dit rapport is gratis te downloaden op: https://doi.org/10.18174/444102

Dit rapport is gebaseerd op de database: Oldenburger, J.F., J.J. Jansen, A. Oosterbaan, H. Lu, G.M.J. Mohren \& J. den Ouden, 2016. FEM growth and yield data Monocultures - Silver birch. DANS. http://dx.doi.org/10.17026/dans-zth-5df8 


\section{Voorwoord}

In Nederland zijn er waarnemingen verricht in permanente proefperken van de ruwe berk (Betula pendula) tussen 1982 en 1994.

Jansen et al. (1996) nemen in hun tabellenboek een bewerking van de tabel van Braastad (1976) op voor de berk (de toevoeging "ruwe" wordt verder in dit verhaal weggelaten). Bartelink et al. (2001) geven een uitgebreid overzicht van de context en publicaties van het groei- en productieonderzoek aan deze en andere boomsoorten in Nederland.

Samen met de permanente steekproefpunten van de HOSP is er de huidige studie de beschikking over de gegevens van 43 plots met 132 opnamen in het tijdvak 1982 tot 1999.

In dit rapport wordt de ontwikkeling van opstanden van berk met verschillende dunninggraden geanalyseerd met het doel een groeimodel te maken bij een ruim scala aan beheerstrategieën. Deze studie is deel van een serie, waarin de groei en productie van douglas (Jansen et al., 2016), Japanse lariks, fijnspar, zomereik, populier, grove den, beuk, Corsicaanse den, Oostenrijkse den, Amerikaanse eik, es en gewone esdoorn werden bestudeerd.

De studie volgt waar mogelijk dezelfde werkwijze als de voorgaande studies en vaak zijn delen van de tekst uit deze rapporten (soms ook zonder bronvermelding) overgenomen. Maar vanaf de Amerikaanse eik en volgende rapporten is er sprake van een vereenvoudigde werkwijze, omdat er beduidend minder gegevens ter beschikking zijn en wordt er ook een opbrengsttabel met één dunninggraad gepresenteerd.

Om de toegankelijkheid voor niet Nederlandse lezer te verhogen zijn alle figuren, en formules en veel tabellen van Engelse tekst voorzien.

Hans Jansen,

Wageningen, 2018 


\section{Inhoud}

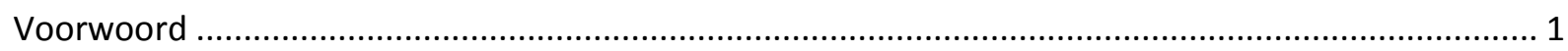

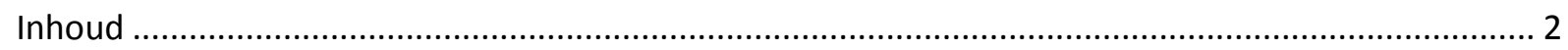

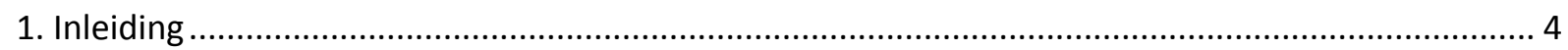

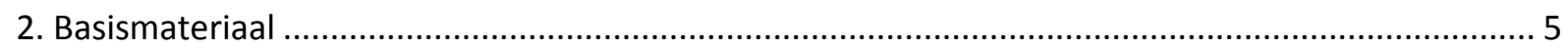

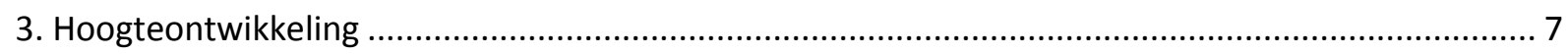

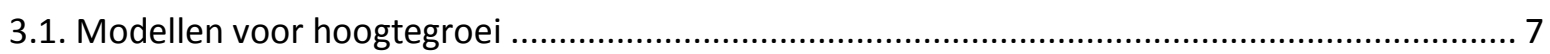

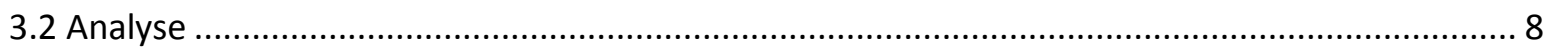

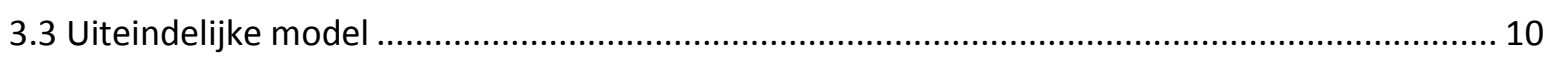

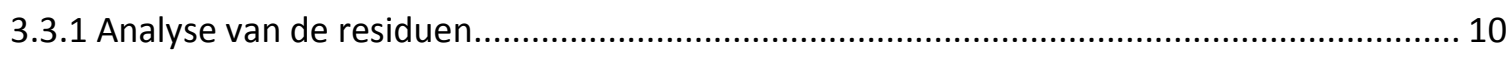

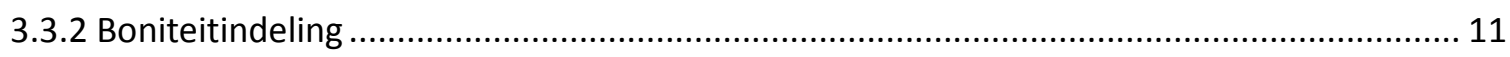

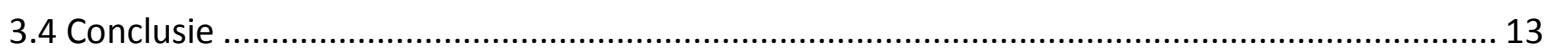

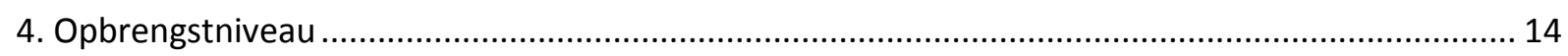

4.1 Diameter- en grondvlakontwikkeling tot een hoogte van $7 \mathrm{~m}$........................................ 14

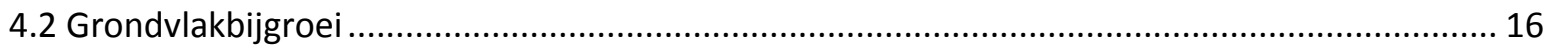

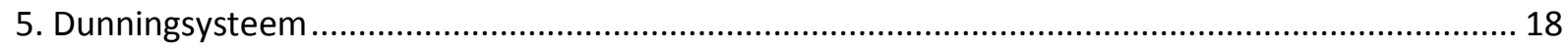

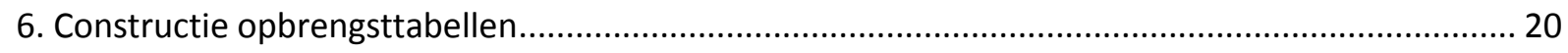

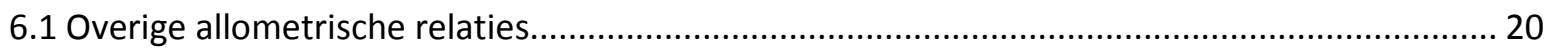

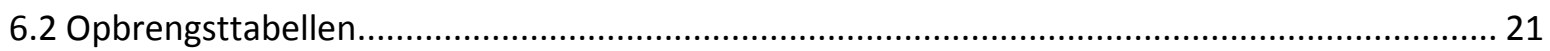

6.3 Vergelijking met andere opbrengsttabellen .................................................................. 22

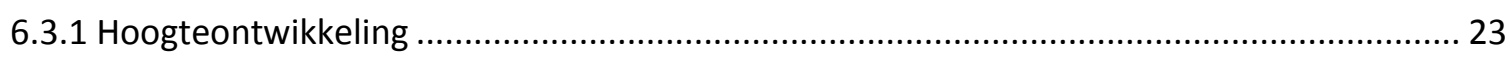

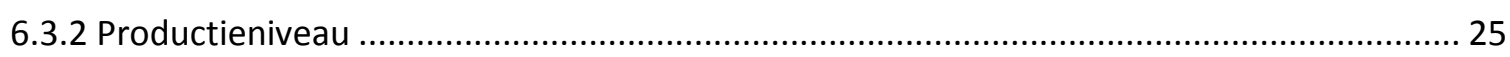

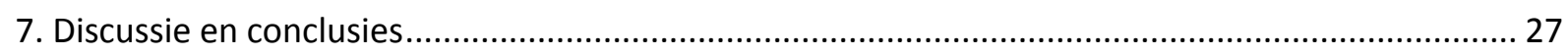

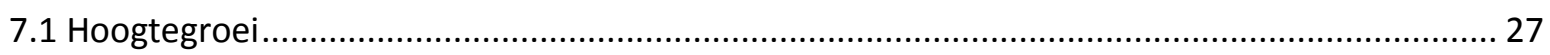

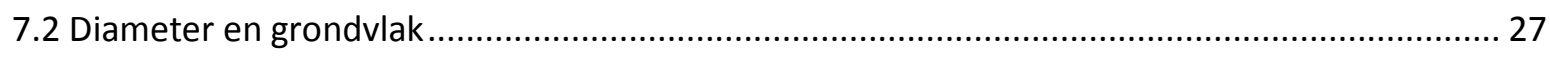

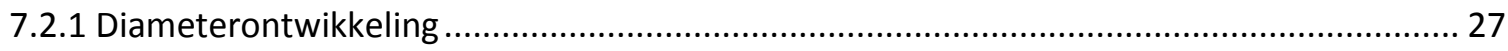

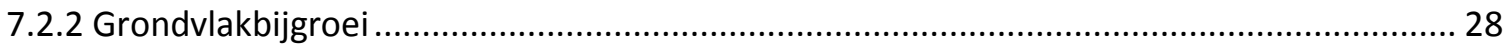

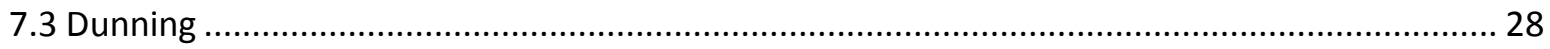

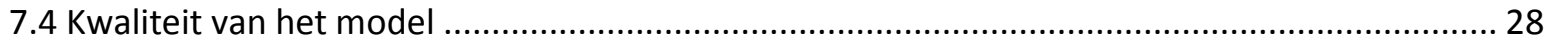

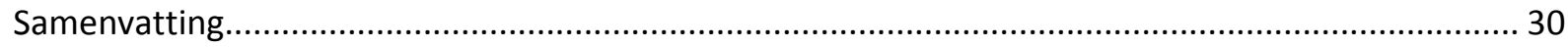

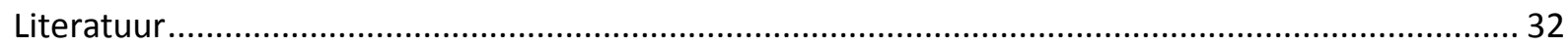

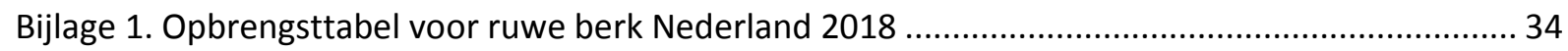

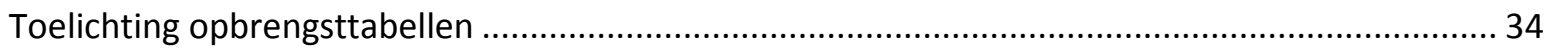

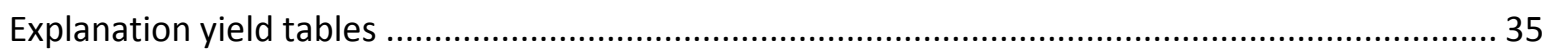


Boniteringfiguur

Sterke laagdunning... 


\section{Inleiding}

Tussen 1982 en 1999 zijn er gegevens verzameld over de groei van berk. Met deze gegevens is het mogelijk modellen te maken die de ontwikkeling van berkenopstanden bij een variatie aan beheerstrategieën verklaren en mogelijk voorspellen. Eén van de gebruikelijke modellen is een opbrengsttabel. Jansen et al. (1996) hebben een opbrengsttabel voor de berk opgenomen dat betreft een OPTAB-simulatie van de tabel van Braastad (1967) voor Noorwegen.

Een opbrengsttabel is een model waarmee de opstandontwikkeling in de tijd wordt beschreven en het bestaat meestal uit drie submodellen:

1. Model voor de hoogteontwikkeling, dit wordt In Hoofdstuk 3 besproken.

2. Model voor de grondvlakbijgroei in de tijd of relatief ten opzichte van de hoogte, waarmee het productieniveau van opstanden kan worden voorspeld, dit wordt In Hoofdstuk 4 besproken.

3. Model voor de dunning. Dit model moet een definitie geven van de dunninggraden, daarnaast is het de vraag wat de interactie is met model ad 2 bij verschillende dunninggraden. In Hoofdstuk 5 komen deze vragen aan de orde.

In hoofdstuk 2 worden de basisgegevens besproken. In Hoofdstuk 6 worden de 3 submodellen geïntegreerd tot een serie opbrengsttabellen. Deze worden vergeleken met andere tabellen. De opbrengsttabellen zijn te vinden in Bijlage 1. 


\section{Basismateriaal}

Sinds 1982 is er in Nederland op bescheiden schaal onderzoek gedaan naar de ontwikkeling van berkenopstanden (Betula pendula) dit betref één studie, gedurende een ongeveer overlappende periode zijn ook steekproefpunten van de HOSP gemonitord:

2. Groei- en productieonderzoek Dorschkamp/IBN 1982 - 1994 ten behoeve van opbrengsttabellen. Er zijn 10 proefperken met 21 opnamen;

4. HOSP 1984-1999, in beheer bij Probos. Dit zijn ca. 3000 permanente steekproefpunten uit de $4 \mathrm{e}$ bosstatistiek. Hieruit zijn 33 monocultures met berk geselecteerd met in totaal 111 opnamen. In de HOSP is slechts één code voor alle berken soorten gebruikt, daardoor is het mogelijk dat er naast ruwe berk ook een enkel perk met zachte berk tussen zit. In de studie is die mogelijkheid verder genegeerd.

In totaal gaat het om 43 opnamen in 132 proefperken.

De proefvelden van studie 1 en 2 betreffen proefvakken met een vaste oppervlakte. Soms wordt die oppervlakte kleiner door stormschade. De gegevens zijn daarna opnieuw berekend over de kleinste oppervlakte. In studie 4 gaat het om vaste steekproefpunten met een variërende straal zodanig dat er minimaal 25 bomen in de steekproef liggen. Door kap of ingroei kan deze wijzigen. Alleen dat deel wat in alle opnamen aanwezig was is bij het onderzoek betrokken.

Voor het bepalen van de dunninggraad is het S-procent van Hart (1928) (ook bekend als de Hart-Becking Spacing Index) van alle perken en opnamen berekend met formule (1):

$$
S \%=\frac{a_{a t}}{h_{\text {top }}} \cdot 100=\frac{100}{h_{\text {top }}} \cdot \sqrt{\frac{10000}{N_{a t}} \cdot \frac{2}{\sqrt{3}}} \approx \frac{10745.7}{h_{\text {top }} \cdot \sqrt{N_{a t}}}
$$

In deze definitie is de gemiddelde boomafstand na dunning $\left(a_{a t}\right)$ bepaald met een regelmatig driehoekverband. Het symbool $h_{\text {top }}$ staat voor de opperhoogte.

Van alle proefperken zijn basisgegevens als oppervlakte, kiemjaar en ligging bekend.

De afzonderlijke metingen en berekeningen aan de bomen in de proefperken vormen de basisgegevens. Deze zijn daarna geaggregeerd tot kenmerken per ha per proefperk van voor, na, en van de dunning. De boomgegevens spelen in deze studie alleen een rol om de opstandkenmerken te genereren.

Per proefperk en opname zijn de gegevens beschikbaar, zoals vermeld in Tabel 1. Voor een volledige beschrijving van gemeten en berekende gegevens zie de file "Read me - FEM growth and yield data Monocultures - silver birch.pdf" in de database FEM growth and yield data Monocultures - silver birch (Oldenburger et al., 2016).

Naast deze gegevens van permanente plots zijn er de hoogte en diameterwaarnemingen tussen 1980 en 1983 uit de $4^{\text {e }}$ Bosstatistiek (1985), voor berk gaat dat om 2683 opstanden. 
Tabel 1. Basisgegevens per plot en opname.

Table 1. Base information per plot and recording

\begin{tabular}{|l|l|l|}
\hline Naam & Symbool & Betekenis \\
\hline plotnr & & Plotnummer \\
region & & Studienummer \\
area & & Regio \\
yog & & Plotoppervlakte in ha \\
NO & $N_{0}$ & Kiemjaar \\
sperc & Beginstamtal \\
sperc0 & $S_{0} \%$ & gemiddelde Hart-Becking Spacing Index in plot \\
nrec & & Actuele Hart-Becking Spacing Index in de opname \\
rec & & Aantal opnamen \\
DOR & & Opname nummer \\
age & $t$ & Datum van de opname \\
htop & $h_{\text {top }}$ & Leeftijd in jr \\
hdom & $h_{d o m}$ & Opperhoogte in $\mathrm{m}$ \\
ddom & $d_{d o m}$ & Dominante hoogte in $\mathrm{m}$ \\
N_bt & $N_{b t}$ & Diameter van de dominante hoogte boom in cm \\
G_bt & $G_{b t}$ & Stamtal per ha voor dunning \\
h_bt & $h_{b t}$ & Grondvlak voor dunning in $\mathrm{m}^{2} /$ ha \\
dg_bt & $d_{b t}$ & Hoogte van de grondvlak-middenstam in $\mathrm{m}$ voor dunning \\
V_bt & $V_{b t}$ & Diameter van de grondvlak-middenstam in $\mathrm{cm}$ voor dunning \\
N_th & $N_{t h}$ & Volume voor dunning in $\mathrm{m}^{3} /$ ha \\
G_th & $G_{t h}$ & Stamtal per ha van de dunning \\
h_th & $h_{t h}$ & Grondvlak van de dunning in $\mathrm{m}^{2} /$ ha \\
dg_th & $d_{t h}$ & Hoogte van de grondvlak-middenstam in $\mathrm{m}$ van de dunning \\
V_th & $V_{t h}$ & Diameter van de grondvlak-middenstam in cm van de dunning \\
N_at & $N_{a t}$ & Volume van de dunning in $\mathrm{m}^{3} /$ ha \\
G_at & $G_{a t}$ & Stamtal per ha na dunning \\
h_at & $h_{a t}$ & Grondvlak na dunning in $\mathrm{m}^{2} /$ ha \\
dg_at & Hoogte van de grondvlak-middenstam in $\mathrm{m}$ na dunning \\
V_at & $d_{a t}$ & Diameter van de grondvlak-middenstam in cm na dunning \\
& & Volume na dunning in $\mathrm{m}^{3} / \mathrm{ha}$ \\
\hline
\end{tabular}




\section{Hoogteontwikkeling}

Voor de hoogteontwikkeling zijn er 43 proefperken met 132 opnamen beschikbaar voor analyse (zie Figuur 1a). Daarnaast is er beschikking over de hoogtegegevens van 2683 opstanden uit de $4^{\mathrm{e}}$ Bosstatistiek (zie Figuur 1b).
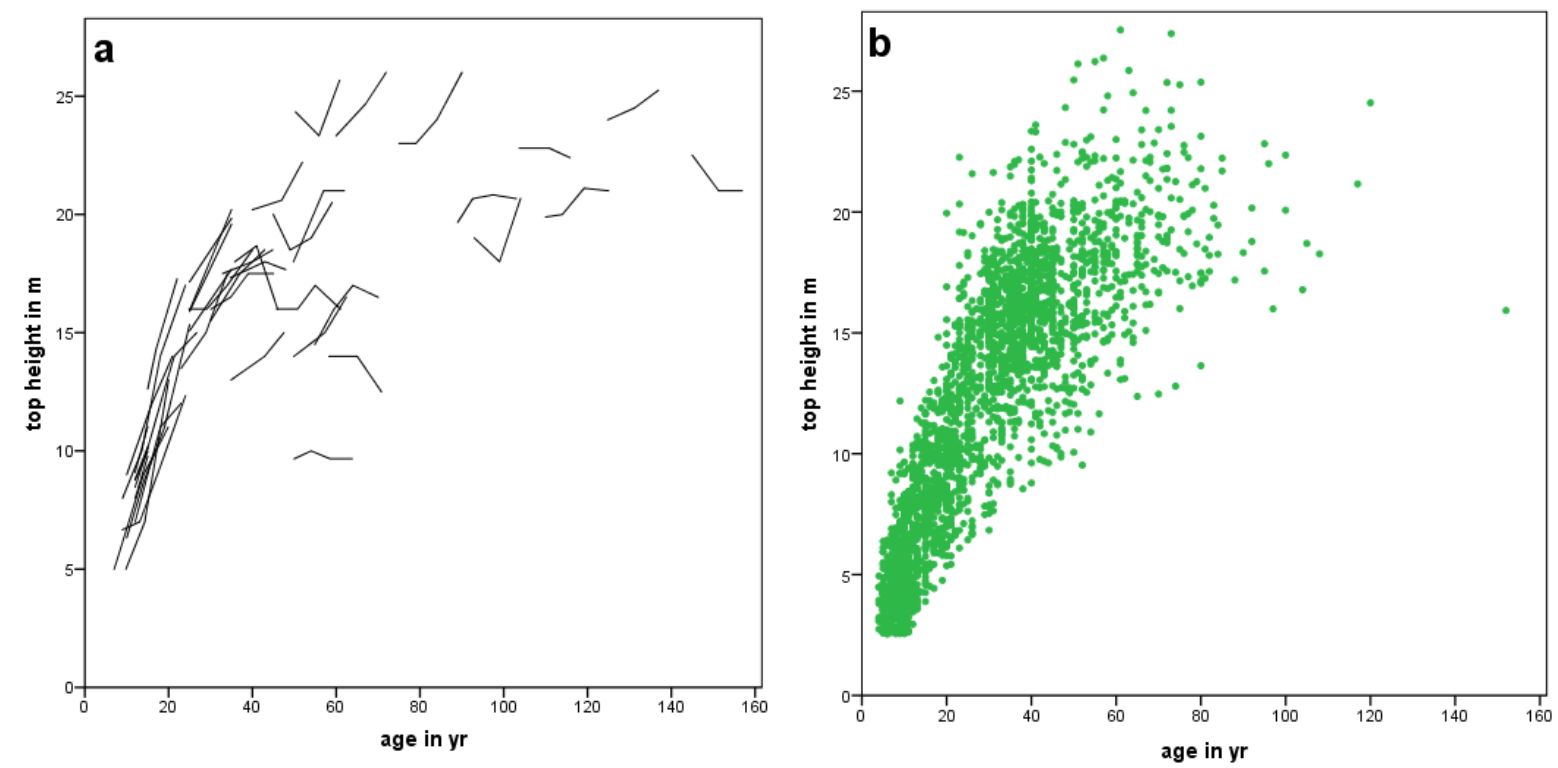

Figuur 1. Hoogteontwikkeling in de proefperken in Nederland (a) en hoogte en leeftijd bij waarnemingen in $4^{e}$ Bosstatistiek (b).

Figure 1. Development of tree height in plots in the Netherlands (a) and height and age at data from Fourth Dutch Forest Inventory (b).

\subsection{Modellen voor hoogtegroei}

In de opbrengsttabellen tot ongeveer 1970 is de hoogteontwikkeling meestal handmatig gefit. Vanaf 1970 worden over het algemeen niet-lineaire groeifuncties gebruikt om de hoogteontwikkeling te fitten. In de huidige Nederlandse opbrengsttabel voor de berk (Faber, 1996) is het Chapman-Richards model gebruikt:

$$
h_{\text {top }}=S \cdot\left(1-e^{-a \cdot t}\right)^{b}
$$

In Formule (2) is S de zogenaamde "site index" de proefperkspecifieke constante en de asymptoot in het model. Deze $S$ kan gezien worden als de afplattingshoogte en het is tevens een maat voor de boniteit, in dit geval een absolute hoogteboniteit. Daarnaast wordt ook de hoogte bij een vaste leeftijd als maat voor de boniteit gebruikt. Voor de berk zal de $h_{50}$ worden gebruikt

De te onderzoeken modellen zijn Chapman-Richards, Burkhart-Tennent, Jansen-Hildebrand, en Cieszewski, zie Paragraaf 3.2 voor formules en referenties. 


\subsection{Analyse}

De volgende vijf modellen zijn onderzocht.

1. Het homomorfe model van Chapman-Richards (zie Pienaar \& Turnbull, 1973):

$$
h_{\text {top }}=S \cdot\left(1-e^{-a \cdot t}\right)^{b}
$$

2. Burkhart \& Tennent (1977) paste het Chapman-Richard model aan door de parameter $a$ als functie van $S$ uit te drukken waardoor een heteromorf model ontstaat:

$$
h_{\text {top }}=S \cdot\left(1-e^{-\left(a_{0}+a_{1} \cdot S\right) \cdot t}\right)^{b}
$$

3. Jansen \& Hildebrand (1986) pasten de werkwijze van Burkhart \& Tennent toe op de $b$-parameter, hierdoor ontstaat eveneens een heteromorf model:

$$
h_{\text {top }}=S \cdot\left(1-e^{-\alpha \cdot t}\right)^{\left(b_{0}-b_{1} \cdot S\right)}
$$

4. Het Cieszewski model (2001) gebruikt een referentieleeftijd $t_{\text {ref luidt het: }}$

$$
h_{\text {top }}=h_{\text {ref }} \cdot \frac{t^{a} \cdot\left(t_{\text {ref }}^{a} \cdot R+b\right)}{t_{r e f}^{a} \cdot\left(t^{a} \cdot R+b\right)}, \text { where } R=Z+\sqrt{Z^{2}+\frac{2 \cdot b \cdot h_{r e f}}{t_{r e f}^{a}}} \text { and } Z=h_{r e f}-c
$$

Dit heteromorfe model heeft wel een asymptoot, maar de oplossing moet gevonden worden met formule (6).

Stap 1. Keuze voor model met data permanente plots.

De parameters die verantwoordelijkheid voor heteromorfe vorm bij de modellen van Jansen \& Hildebrand, van Burkhart \& Tennent en Cieszewski bleken niet significant. Het ChapmanRichards model, verklaarde het meest van de variantie $\left(R^{2} \mathrm{adj}=0.973\right)$.

De data van Figuur 1b onderbouwen de veronderstelleng van een homomorf model een juiste keuze echter nauwelijks.

Een groot probleem bij de data van Figuur 1a zijn de zeer korte tijdseries.

Stap 2. Keuze voor model met data $4^{\mathrm{e}}$ Bosstatistiek. Jansen et al. (2018) gebruikten voor de zwarte els een methode waarbij de data van de $4^{e}$ Bosstatistiek in vier deelverzamelingen werden ingedeeld per te onderzoeken model. Ze berekenen uiteindelijk een boven- en ondergrens voor de data. Met de gevonden parameters zijn de schattingen van de hoogten voor deze beide grenslijnen berekend en tezamen met de data uit de $4^{\mathrm{e}}$ Bosstatistiek gepresenteerd in Figuur 2.

In Tabel 2 zijn enige eigenschappen van de oplossingen per model weergegeven:

1. De algemene maat voor de verklaring, hiervoor is $R^{2}$ adj gebruikt;

2. De kwaliteit van de schatter van boniteit-parameters door naar de variatiecoëfficiënt COV ervan te kijken, hoe kleiner deze is hoe nauwkeuriger de boniteit bepaling is; 
3. De $h_{50}$ met de gemiddelde waarde en interval, volgens Figuur $1 \mathrm{~b}$ moet dat gemiddelde ongeveer $17 \mathrm{~m}$ zijn en tussen de 12 en $22 \mathrm{~m}$ liggen, maar erg nauwkeurig is dit niet vast te stellen;

4. De model-parameter $S$ en een $95 \%$ betrouwbaarheidsinterval ervan, en getoetst of deze overeenkomt met de te verwachten maximale afplattingshoogte. De hoogst gemeten opperhoogte in de permanente plots bleek $26 \mathrm{~m}$ bij een leeftijd van $72 \mathrm{jr}$. en in de 4e bosstatistiek (CBS, 1985) was dat $28 \mathrm{~m}$ bij $61 \mathrm{jr}$. De maximale $S$-waarde voor de beste boniteit voor de berk in Nederland zal daarom ruim 30 m moeten bedragen;

5. De leeftijd waarop de borsthoogte wordt bereikt. Op het tijdstip 0 moet de hoogte ook 0 $\mathrm{m}$ zijn, daarna moet de groei in het eerste jaar langzaam op gang komen om vervolgens zeer snel te groeien en meestal zal $t_{130}$ tussen het $2^{\mathrm{e}}$ en $5^{\mathrm{e}}$ jaar worden bereikt;

6. Het al dan significant en relevant zijn van alle parameterschattingen;

7. Het percentage punten (out\%) wat buiten de grenzen Figuur 2 valt.

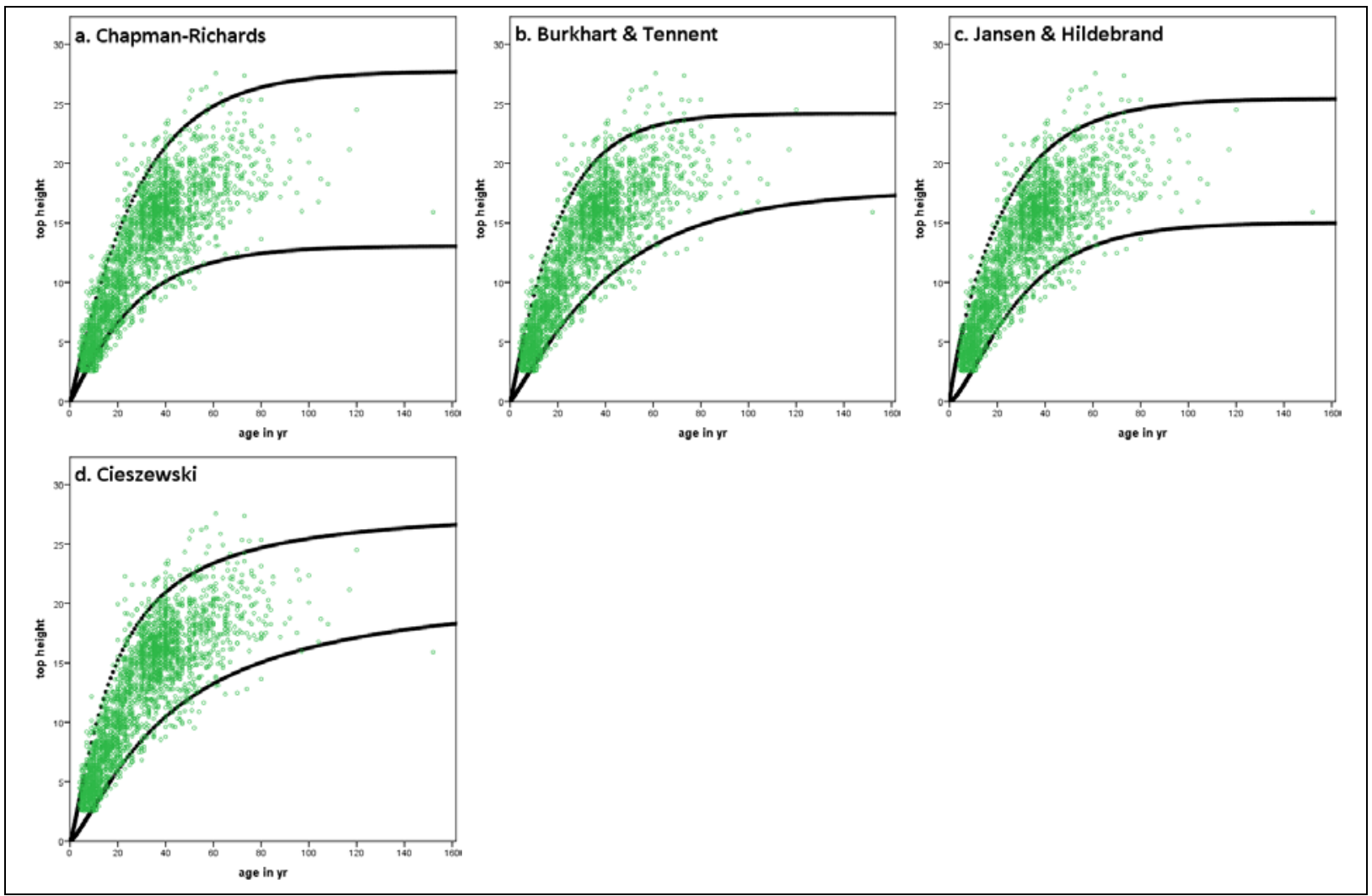

Figuur 2. Hoogtewaarnemingen in $4^{e}$ Bosstatistiek en curven van de laagste en hoogste boniteit per model.

Figure 2. Top height observations in Fourth Dutch Forest Inventory with lowest and highest site curves per model.

In een Multi Criteria Analyse met gelijk gewicht zijn de modellen op basis van deze 7 eigenschappen vergeleken. Daarmee is de keuze gevallen op het model van Cieszewski. Het beeld van Figuur $2 \mathrm{~d}$ versterkt deze keuze. 
Tabel 2. Resultaten van niet-lineaire regressie met de geselecteerde modellen in MCA.

Table 2. Results of nonlinear regression for the selected models in MCA.

\begin{tabular}{|c|c|c|c|c|c|c|c|c|c|c|}
\hline & model & npar & $R^{2}$ adj & COV_SI & h50 & $S$ & $t_{130}$ & s/ns & out \% & result \\
\hline \multirow{4}{*}{$\frac{\frac{y}{2}}{\frac{\partial}{\pi}}$} & Chapman-Richards & 2 & 0.968 & 0.7 & $17\{11 ; 23\}$ & $20\{13 ; 28\}$ & $3\{2 ; 3\}$ & $\mathrm{s}$ & 11.1 & 4 \\
\hline & Burkhart \& Tennent & 3 & 0.971 & 0.8 & $17\{12 ; 22\}$ & $21\{18 ; 24\}$ & $3\{1 ; 4\}$ & $\mathrm{s}$ & 6.9 & 3 \\
\hline & Jansen \& Hildebrand & 3 & 0.971 & 0.6 & $17\{12 ; 22\}$ & $20\{15 ; 25\}$ & $3\{1 ; 6\}$ & $\mathrm{s}$ & 6.3 & 2 \\
\hline & Cieszewski & 3 & 0.971 & 0.3 & $17\{12 ; 22\}$ & $25\{21 ; 28\}$ & $3\{2 ; 5\}$ & $\mathrm{s}$ & 6.8 & 1 \\
\hline \multirow{4}{*}{ م. } & Chapman-Richards & 2 & 4 & 3 & 4 & 2 & 4 & 2.5 & 4 & 24 \\
\hline & Burkhart \& Tennent & 3 & 3 & 4 & 2 & 4 & 2 & 2.5 & 3 & 21 \\
\hline & Jansen \& Hildebrand & 3 & 1 & 2 & 2 & 3 & 3 & 2.5 & 1 & 15 \\
\hline & Cieszewski & 3 & 2 & 1 & 2 & 1 & 1 & 2.5 & 2.0 & 12 \\
\hline
\end{tabular}

Met de gevonden parameters bij het model van Cieszewski zijn de voorspelde hoogten berekend voor alle vier deelverzamelingen voor de leeftijden 5, 10,15 .... 100 jaar. Hierdoor ontstaan 4 kunstmatige plots met 20 "waarnemingen".

\subsection{Uiteindelijke model}

In formule (7) en alle volgende vergelijkingen die een onderdeel van het opbrengstmodel vormen worden de parameters genummerd als $c_{1}, c_{2}$ enzovoorts. Het model van Cieszewski luidt voor een referentieleeftijd van 50 jaar:

$$
h_{\text {top }}=h_{50} \cdot \frac{t^{c_{1}} \cdot\left(50^{c_{1}} \cdot R+c_{2}\right)}{50^{c_{1}} \cdot\left(t^{c_{1}} \cdot R+c_{2}\right)}, \text { where } R=Z+\sqrt{Z^{2}+\frac{2 \cdot c_{2} \cdot h_{50}}{50^{c_{1}}}} \text { and } Z=h_{50}-c_{3}
$$

Model (7) is daarna opnieuw gefit met de gezamenlijke 132 waarnemingen van de 43 permanente plots van Figuur 1a en de 20 paren $\left(h_{\text {top }}, t\right)$ voor de vier kunstmatige plots uit de 4 e Bosstatistiek. Met een $R^{2}$ adj van 0.986 werden de parameters van Tabel 3 gevonden.

Tabel 3. Parameters voor Model (7).

Table 3. Parameters for Model (7).

\begin{tabular}{|l|r|r|r|r|}
\hline & & & \multicolumn{2}{|c|}{ 95\% Confidence Interval } \\
\cline { 4 - 5 } Parameter & Estimate & Std. Error & \multicolumn{1}{|c|}{ Lower Bound } & \multicolumn{1}{c|}{ Upper Bound } \\
\hline$c_{1}$ & 1.3198 & 0.048 & 1.225 & 1.415 \\
$c_{2}$ & 1065.6372 & 283.975 & 504.868 & 1626.406 \\
$c_{3}$ & 16.4603 & 2.048 & 12.416 & 20.504 \\
\hline
\end{tabular}

\subsubsection{Analyse van de residuen}

In Figuur 3 zijn de residuen van de NLR met Formule (7) zijn uitgezet tegen de systeemvariabele leeftijd en de afgeleide systeemvariabele $h_{50}$. Er is geen onzuiverheid te zien en er zijn twee uitbijters aanwezig. 

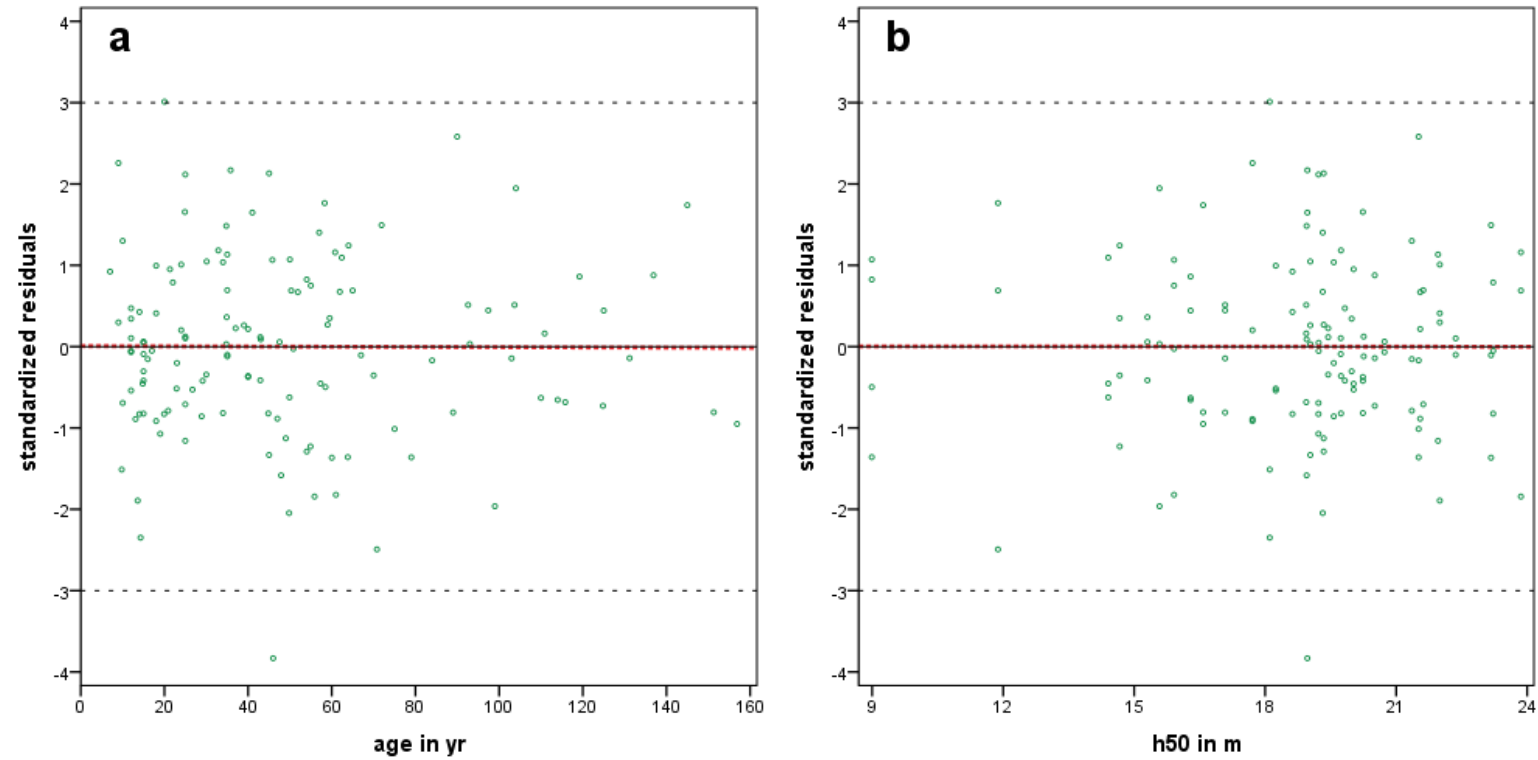

Figuur 3. Gestandaardiseerde residuen in relatie tot leeftijd (a) en $h_{50}(b)$, de rode lijn geeft de lineaire fit weer.

Figure 3. Standardized residuals in relation to top height (a) and $h_{70}(b)$, the red line is the linear fit.

\subsubsection{Boniteitindeling}

Met de gegevens van de $4^{\mathrm{e}}$ bosstatistiek (CBS, 1985) is van 2683 monocultures met berk de $h_{50}$ bepaald volgens de methode van Jansen et al. (2016). Dit leidt tot de verdeling over de $h_{50}$ zoals weergegeven in Figuur 4.

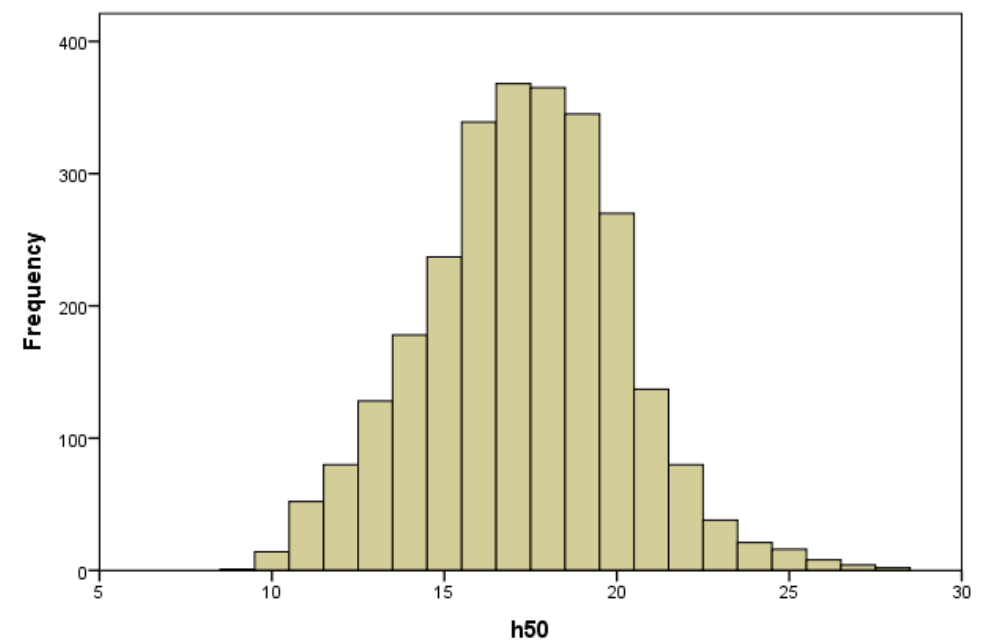

Figuur 4. Frequentiehistogrammen van $h_{50}$ in $4 e$ bosstatistiek.

Figure 4. Frequency histogram of $h_{50}$ per forest region in the Fourth Dutch Forest Inventory.

Het frequentiehistogram van Figuur 4 is heeft bij benadering een normale verdeling. Er is gekozen om het deel tussen 10.6 en $24.6 \mathrm{~m}$ in 5 boniteiten in te delen. Zie Tabel 4 voor het resultaat. Met deze indeling heeft $1.0 \%$ van alle opstanden van de berk een betere boniteit dan de $\mathrm{I}^{\mathrm{e}}$ en $0.7 \%$ heeft een slechtere boniteit dan de $\mathrm{V}^{\mathrm{e}}$.

De beste boniteiten blijken iets oververtegenwoordigd in de dataset. 
Tabel 4. Indeling in boniteiten gebaseerd op de $\boldsymbol{h}_{50}$.

Table 4. Classification in site classes based on the $h_{50}$.

\begin{tabular}{|c|c|c|c|c|}
\hline $\begin{array}{c}\text { Boniteit } \\
\text { site class }\end{array}$ & $\begin{array}{c}\boldsymbol{h}_{\mathbf{5 0}} \\
\boldsymbol{h}_{50}\end{array}$ & $\begin{array}{c}\text { Bereik } \boldsymbol{h}_{\mathbf{5 0}} \\
\text { range } h_{50}\end{array}$ & $\begin{array}{c}\text { \% in dataset } \\
\text { \% in data set }\end{array}$ & $\begin{array}{c}\text { \% in } \mathbf{4}^{\mathrm{e}} \text { Bosstatistiek } \\
\text { \% in 4th forest inventory }\end{array}$ \\
\hline$<$ I & & $>24.6$ & & 1.0 \\
I & 23.2 & $(21.8-24.6)$ & 12.9 & 3.9 \\
II & 20.4 & $(19.0-21.8)$ & 43.9 & 22.3 \\
III & 17.6 & $(16.2-19.0)$ & 25.0 & 37.9 \\
IV & 14.8 & $(13.4-16.2)$ & 12.9 & 25.2 \\
V & 12.0 & $(10.6-13.4)$ & 2.3 & 8.9 \\
$>$ V & & $<10.6$ & 3.0 & 0.7 \\
\hline
\end{tabular}

In Tabel 5 is te zien dat er een redelijk homogene verdeling is over de leeftijdsklassen en boniteiten, behoudens bij bos tot 10 jaar bij de I $^{\mathrm{e}}$ boniteit.

Tabel 5. Aantal opstanden per leeftijdsklassen en boniteit in $4^{\mathrm{e}}$ Bosstatistiek.

Table 5. Age classes per site class in Fourth National Forest Inventory (number of stands).

\begin{tabular}{|c|rrrrr|r|}
\hline leeftijdsklasse & \multicolumn{1}{|c}{ I } & II & III & IV & $\mathbf{\geq V}$ & totaal \\
\hline $0-10$ & 48 & 106 & 122 & 104 & 27 & 407 \\
$10-20$ & 9 & 106 & 175 & 170 & 83 & 543 \\
$20-30$ & 22 & 116 & 138 & 98 & 50 & 424 \\
$30-40$ & 25 & 164 & 312 & 115 & 28 & 644 \\
$40-50$ & 10 & 48 & 135 & 94 & 39 & 326 \\
$50-60$ & 9 & 28 & 80 & 42 & 17 & 176 \\
$60-70$ & 4 & 15 & 30 & 28 & 10 & 87 \\
$70-80$ & 5 & 11 & 16 & 13 & 3 & 48 \\
$\geq 80$ & & 3 & 10 & 12 & 3 & 28 \\
\hline Totaal & 132 & 597 & 1018 & 676 & 260 & 2683 \\
\hline
\end{tabular}

In Figuur 5 is de hoogteontwikkeling per boniteit samen met die van de proefperken en met die van de gegevens van de $4^{\mathrm{e}}$ Bosstatistiek weergegeven. 

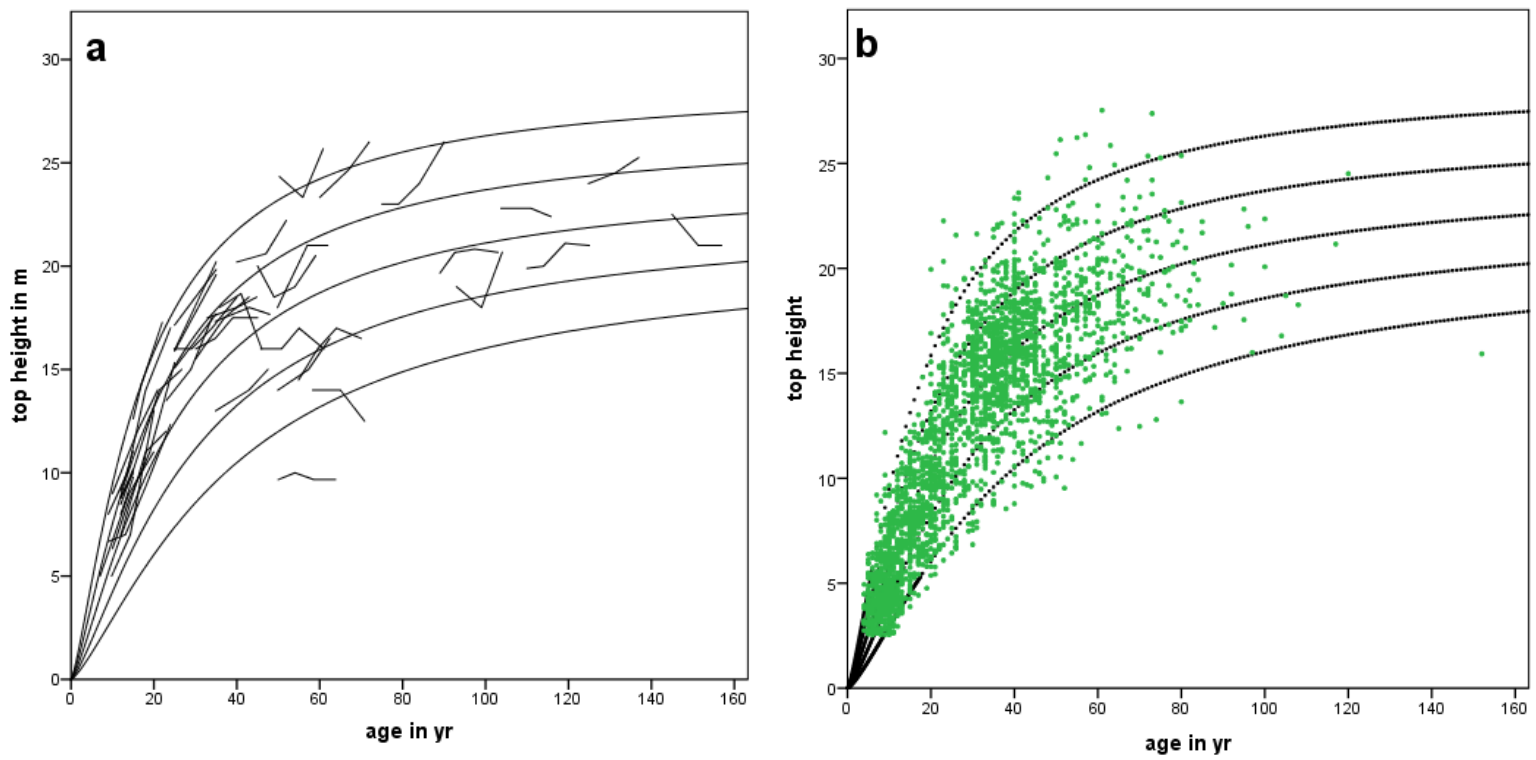

Figuur 5. Boniteitcurven voor de berk in Nederland met de hoogteontwikkeling van de proefperken(a) en met de waarnemingen van de $4^{e}$ Bosstatistiek (b).

Figure 5. Top height development with site curves for silver birch at experimental plots (a) and at data Fourth National Forest inventory (b).

\subsection{Conclusie}

De hoogtegroei van de berk is onderzocht en het model van Cieszewski is gekozen. Hiermee is een indeling in 5 boniteiten gemaakt. Slechts $1 \%$ van de berkbossen in Nederland heeft een betere boniteit dan de hier gepresenteerde boniteit I en bijna $1 \%$ heeft een lagere boniteit dan boniteit $\mathrm{V}$. 


\section{Opbrengstniveau}

Naast de hoogtegroei vindt ook diktegroei plaats. Dit resulteert in diameterbijgroei $i_{d}=\left(d_{2}-d_{1}\right) /\left(t_{2}-t_{1}\right)$ en grondvlakbijgroei $i_{G}=\left(G_{2}-G_{1}\right) /\left(t_{2}-t_{1}\right)$. Hoogtegroei en diktegroei samen resulteren in een volumebijgroei. In opbrengsttabellen is een belangrijk doel juist de volumebijgroei te bepalen. Aangezien het boomvolume in de dataset een afgeleide, berekende variabele is en niet berust op een primaire waarneming, zal ook de volumebijgroei indirect worden berekend. Diameter en het totale grondvlak zullen in de loop van de tijd toenemen, maar gelijktijdig neemt ook de hoogte toe.

Jansen et al. (2016) onderzochten voor douglas een aantal groeimodellen. Ze vonden dat tot een opperhoogte van $7 \mathrm{~m}$ de opstandontwikkeling het best kan worden verklaard met een voorspelling van de diameter voor dunning. Vanaf een opperhoogte $7 \mathrm{~m}$ werd de opstandontwikkeling beter verklaard door de grondvlakbijgroei. In Paragraaf 4.1 zal de diameterontwikkeling en daaraan gekoppeld de grondvlakontwikkeling worden geanalyseerd en gemodelleerd. In Paragraaf 4.2 zal de grondvlakbijgroei vanaf een hoogte van $7 \mathrm{~m}$ worden geanalyseerd en gemodelleerd.

\subsection{Diameter- en grondvlakontwikkeling tot een hoogte van $7 \mathrm{~m}$}

Als maat voor de diameter is gekozen voor de "gemiddelde" diameter van de opstand voor dunning $\left(d_{b t}\right)$. Onder "gemiddelde" wordt hier verstaan het kwadratische gemiddelde. Het gaat dus om de $d_{g}$, maar de toevoeging $g$ (van gemiddeld grondvlak) is weggelaten. In Figuur 6a zijn de data van opstanden met een hoogte tot $7.5 \mathrm{~m}$ uit de $4^{\mathrm{e}}$ Bosstatistiek (CBS, 1985) weergegeven, met de beste fittende powerfunctie en in Figuur $6 \mathrm{~b}$ de data uit de proefperken tot en met een hoogte van $10 \mathrm{~m}$.
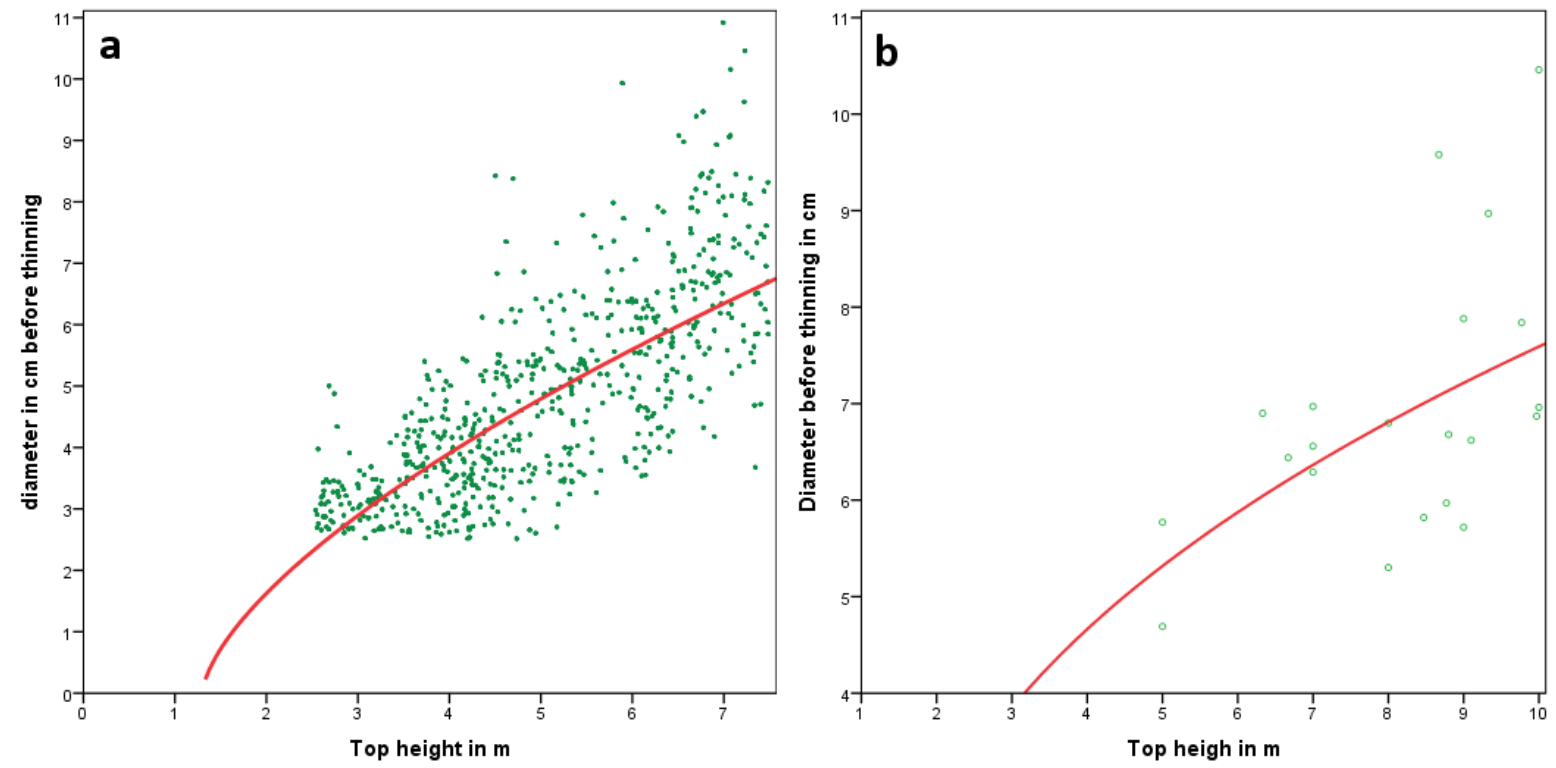

Figuur 6. Diameter en opperhoogte bij data $4^{e}$ Bosstatistiek (a) en bij data proefperken (b) met in rood de beste fit met een powerfunctie.

Figure 6. Diameter and top height in data Fourth National Forest Inventory (a) an in data permanent plots (b). The red lines represent the best fit with a power function. 
Met de proefperken kan een formule voor $d_{7}$ worden ontwikkeld op basis van beginstamtal of de gemiddelde boomafstand, maar in data van de $4^{\mathrm{e}}$ Bosstatistiek zijn die gegevens niet beschikbaar en is $d_{7}$ een te schatten parameter.

Voor de ontwikkeling tot een hoogte van $7 \mathrm{~m}$ is het volgende model gebruikt:

$$
g_{b t}=\pi \cdot\left(\frac{d_{b t}}{200}\right)^{2}=\pi \cdot\left(\frac{d_{7}}{200}\right)^{2} \cdot\left\{\left(\frac{h_{\text {top }}-1.30}{7-1.30}\right)^{c_{4}}\right\}^{2} \text { for } h_{\text {top }} \leq 7 \mathrm{~m} \quad \text { where } d_{7}=c_{5}
$$

Met 637 waarnemingen, een $R^{2}$ adj $=0.565$ is model (8) opgelost met de parameterschattingen van Tabel 6.

Met een $R^{2}$ adj $=0.704$ en 21 waarnemingen in de proefperken met een hoogte tot en met $10 \mathrm{~m}$ wordt gevonden:

$$
g_{b t}=\pi \cdot\left(\frac{d_{b t}}{200}\right)^{2}=\pi \cdot\left(\frac{d_{7}}{200}\right)^{2} \cdot\left\{\left(\frac{h_{\text {top }}-1.30}{7-1.30}\right)^{c_{4}}\right\}^{2} \text { for } h_{\text {top }} \leq 10 \mathrm{~m}
$$

where $d_{7}=c_{5}+c_{6} \cdot a_{b t}$ and $a_{b t}=$ mean tree distance before thinning

Zie Tabel 6 voor de parameterschattingen van model (9).

Tabel 6. Parameters voor Model (8), (9) en (10)

Tabel 6. Parameters for Model (8), (9) en (10)

\begin{tabular}{|c|l|r|r|r|r|}
\hline & & & & \multicolumn{2}{|c|}{ 95\% Confidence Interval } \\
\cline { 4 - 6 } model & Parameter & Estimate & Std. Error & Lower Bound & Upper Bound \\
\hline$(8)$ & $C_{4}$ & 0.7939 & 0.034 & 0.728 & 0.860 \\
$(8)$ & $C_{5}$ & 6.9212 & 0.069 & 6.786 & 7.057 \\
\hline$(9)$ & $C_{4}$ & 0.7889 & 0.146 & 0.482 & 1.096 \\
$(9)$ & $C_{5}$ & 2.1988 & 0.725 & 0.676 & 3.722 \\
$(9)$ & $C_{6}$ & 1.5870 & 0.266 & 1.029 & 2.145 \\
\hline$(10)$ & $C_{4}$ & 0.7914 & & & \\
$(10)$ & $C_{5}$ & 5.7659 & & & \\
\hline
\end{tabular}

De waarde van $d_{7}$ in de proefperken bedraagt voor $N_{0}=5000$ en Formule (9) $4.61 \mathrm{~cm}$ en met Formule (8) met de data van de $4^{\mathrm{e}}$ Bosstatistiek is dat $6.92 \mathrm{~cm}$. De verschillen zijn enorm, besloten is het gemiddelde van beide oplossing aan te houden in Formule (10):

$$
d_{b t}=d_{7} \cdot\left(\frac{h_{\text {top }}-1.30}{7-1.30}\right)^{c_{4}} \text { for } h_{\text {top }} \leq 7 \mathrm{~m} \quad \text { where } d_{7}=c_{5}
$$




\subsection{Grondvlakbijgroei}

Bij de analyse van de grondvlakbijgroei is als grens is een opperhoogte van $7 \mathrm{~m}$ aangehouden, ontwikkeling van het grondvlak tot die hoogte is in Paragraaf 4.1 al besproken. Hier wordt de groei vanaf een opperhoogte van $7 \mathrm{~m}$ behandeld.
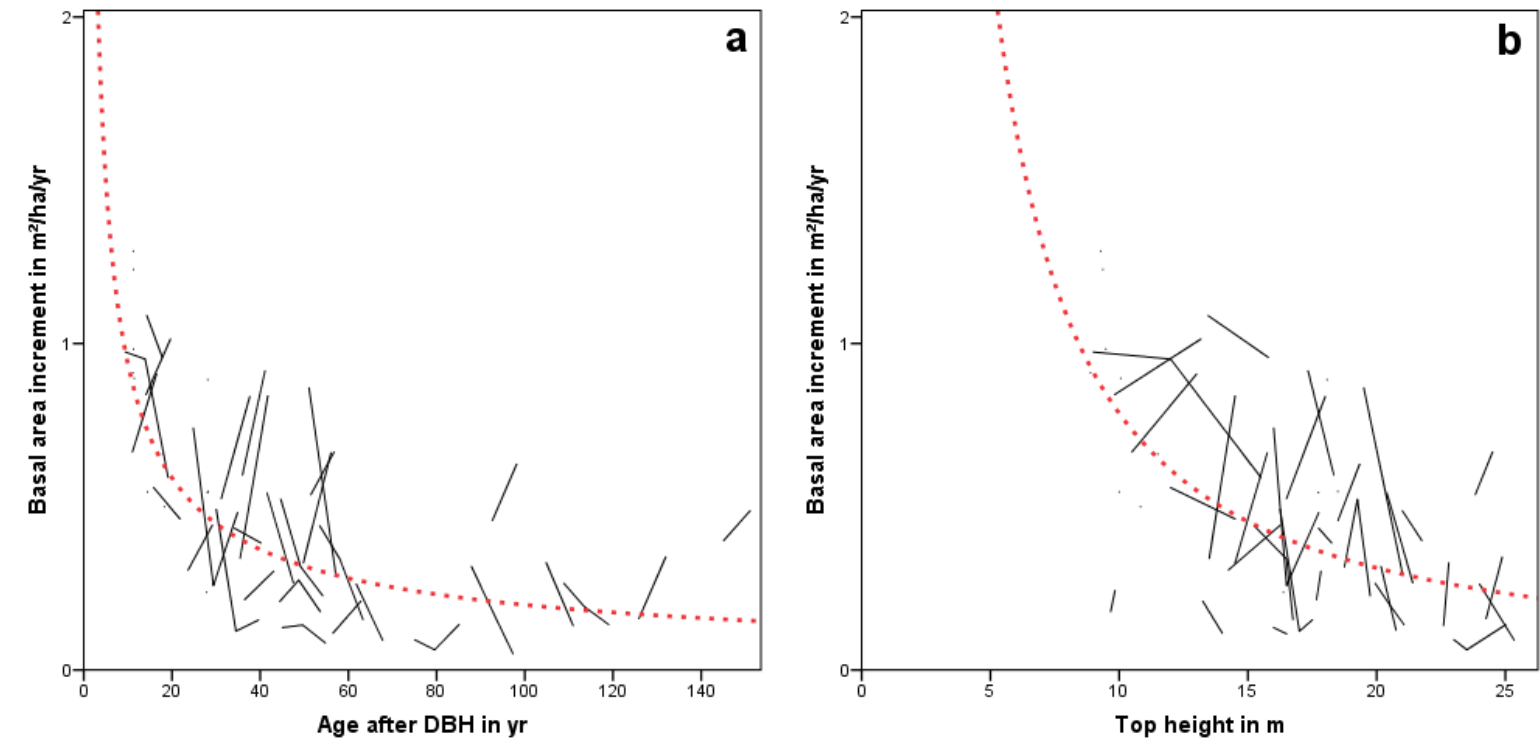

Figuur 7. Grondvlakbijgroei als functie van de leeftijd (a) en opperhoogte (b). De zwarte lijnen geven het verloop binnen één plot aan, de rode lijn de beste fit voor een power-functie over alle opnamen.

Figure 7. The basal area increment as a function of age (a) and top height (b). The black line represents the course within one plot, the red line represents the best fit with a power function.

De grondvlakbijgroei betreft een berekende waarneming tussen 2 opnamen, de leeftijd en opperhoogte betreffen dan het gemiddelde tussen beide opnamen.

Totaal zijn er 82 opnamen beschikbaar voor de analyse, zie Figuur 7 voor de data.

Jansen et al. (2016) ontwikkelden voor de grondvlakbijgroei van douglas het volgende model:

$$
i_{G, j i k}=Y I_{j} \cdot P L_{k} \cdot f_{1}(S \%) \cdot f_{2}\left(h_{\text {ref }}\right) \cdot\left\{\frac{F_{3}\left(h_{2}, t_{2}\right)-F_{3}\left(h_{1}, t_{1}\right)}{\Delta t}\right\}
$$

where $Y I=$ year index and $P L=$ plot level

Voor de douglas bleek $f_{2}$ geen significante bijdrage te leveren.

Hierin is $F_{3}$ een power-functie. In de Figuren $7 \mathrm{a}$ en $7 \mathrm{~b}$ zijn de afgeleiden van $F_{3}$ naar $t$ en $h_{\text {top }}$, in beide gevallen dus weer een powerfunctie, getekend. Op grond daarvan mag geconstateerd worden dat een powermodel zoals Jansen et al. (2016) gebruiken geschikt is om de grondvlakbijgroei te verklaren. Het uitgewerkte model zonder jaarindex $Y I$ of de correctiefactoren $c f_{80}$ voor de periode voor en na 1980 en zonder plotniveau luidt: 


$$
\begin{aligned}
& i_{G}=\operatorname{cor}_{5 \%} \cdot c_{8} \cdot \sqrt{h_{50}} \cdot\left\{c_{12} \cdot \operatorname{Term}_{h} / d t+\left(1-c_{12}\right) \cdot \text { Term }_{t} / d t\right\} \\
& \text { where } \operatorname{Term}_{h}=\left(h_{2 c}-1.30\right)^{c_{11}}-\left(h_{1}-1.30\right)^{c_{11}} \\
& \operatorname{Term}_{t}=\left(t_{2}-t_{130}\right)^{c_{11}}-\left(t_{1}-t_{130}\right)^{c_{11}} \\
& t_{1}=t_{i, j} \text { and } t_{2}=t_{i, j+1} \text { for the } j^{\text {th }} \text { record in the } i^{\text {th }} \text { plot } \\
& h_{2 c}= \begin{cases}h_{2} & \text { for } h_{2}>h_{1} \\
h_{1}+\hat{h}_{2}-\hat{h}_{1} & \text { for } h_{2} \leq h_{1}\end{cases} \\
& h_{1} \text { and } h_{2} \text { are the top heights at time } t_{1} \text { and } t_{2} \\
& \operatorname{cor}_{S \%}= \begin{cases}1 & \text { for } S \%_{0} \leq c_{10} \\
1-c_{9} \cdot \sqrt{S \%_{0}-c_{10}} & \text { for } S \%_{0}>c_{10}\end{cases} \\
& S \%_{0}=\text { Hart-Becking spacing index after thinning at time } t_{1}
\end{aligned}
$$

Met $R^{2}$ adj $=0.595$ en standaarddeviatie $0.19 \mathrm{~m}^{2} \mathrm{jr}^{-1} \mathrm{ha}^{-1}$ werden de parameters van Tabel 7 gevonden. Voor de douglas bleek de toevoeging van de leeftijd geen extra verklaring te geven, voor de berk is die wel van belang en $f_{2}$ speelt in tegenstelling tot de douglas wel een rol. In een daarna uitgevoerde regressiediagnose kwamen geen punten van nader onderzoek aan de orde.

Tabel 7. Parameterschatting met Model (12)

Table 7. Parameter estimation of Model (12)

\begin{tabular}{|l|rrrr|}
\hline & \multicolumn{3}{c|}{ 95\% Confidence Interval } \\
Parameter & \multicolumn{1}{|c}{ Estimate } & \multicolumn{1}{c|}{ Std. Error } & Lower Bound & Upper Bound \\
\hline$c_{8}$ & 1.3952 & 0.519 & 0.362 & 2.428 \\
$c_{9}$ & 0.0542 & 0.023 & 0.009 & 0.100 \\
$c_{10}$ & 19.4648 & 2.751 & 13.988 & 24.942 \\
$c_{11}$ & 0.5624 & 0.089 & 0.386 & 0.739 \\
$c_{12}$ & 0.4384 & 0.132 & 0.175 & 0.702 \\
\hline
\end{tabular}




\section{Dunningsysteem}

In de dunningproeven van studie 1 en 2 zijn verschillende vaste dunninggraden nagestreefd (zie Tabel 8).

Tabel 8. Dunninggraden

Table 8. Thinning grades

\begin{tabular}{|c|c|l|}
\hline Tgr $\boldsymbol{r}_{\mathbf{0}}$ & S\% bij $\mathbf{5 0} \mathbf{~ j r}$ & Omschrijving \\
\hline 1 & 13 & zonder dunning \\
2 & 16 & zwakke laagdunning \\
3 & 19 & matige laagdunning \\
4 & 22 & sterke laagdunning \\
5 & 25 & zeer sterke laagdunning \\
6 & 28 & open stand \\
\hline
\end{tabular}

Er is reden om aan te nemen dat de dunninggraad, zoals hier gedefinieerd via het $S \%$, op latere leeftijd moet stijgen omdat de vorm wijzigt zodra topsterfte optreedt.

Het model luidt dan:

$$
S \%= \begin{cases}13+3 \cdot\left(\operatorname{Tg}_{0}-1\right) & \text { age } \leq 50 \\ 13+3 \cdot\left(\operatorname{Tg}_{0}-1\right)+c_{13} \cdot(\text { age }-50) & \text { age }>50\end{cases}
$$

Vanaf de eerste dunning of sterfte tot een leeftijd van 50 jaar komt het $S \%$, behorend bij de in te stellen dunninggraad $T g r_{0}$, overeen met die uit de tweede kolom van de tabel, daarna loopt het $S \%$ langzaam op.

Een model om $c_{13}$ te schatten luidt:

$$
S \%_{i j}=\left\{\begin{array}{ll}
S \%_{j} & \text { age } \leq 50 \text { and } h_{\text {top }}>7 \\
S \%_{j}+c_{13} \cdot\left(a g e_{i j}-50\right) & \text { age }>50 \text { and } h_{\text {top }}>7
\end{array} \text { for the } i^{\text {th }} \text { record in the } j^{\text {th }}\right. \text { plot }
$$

Met 82 waarnemingen en $R^{2}$ adj $=0.837$ bleek $c_{13}=0.1466$ maar deze waarde was niet significant. In vier vergeleken opbrengsttabellen (zie Tabel 9) werd een gemiddelde waarde van $c_{13}=0.0956$ gevonden, deze waarde is gebruikt. De dunninggraden hebben dus niet langer een vast maar een variabel $S \%$.

Tabel 9. Verloop $S \%$ in vergeleken opbrengsttabellen vanaf $\mathbf{5 0}$ jaar.

\begin{tabular}{|c|c|c|c|}
\hline Tabel & land & S\% bij 50\% & $\Delta \mathrm{S} \% / \mathrm{jr}$ \\
\hline Jansen et al., 1996 & Nederland & 24.6 & 0.1250 \\
\hline Schwappach, 1903 & Duitsland & 25.5 & 0.1864 \\
\hline Lockow, 1996 & Duitsland & 22.6 & 0.0302 \\
\hline Hamilton \& Christie, 1973 & Verenigd Koninkrijk & 33.5 & 0.0407 \\
\hline
\end{tabular}

Table 9 . Course of $S \%$ in compared yield tables from 50 year and up. 
Jansen et al. (2016) voorspellen de diameter na dunning met een modificatie van het model van La Bastide \& Faber (1972):

$$
\begin{aligned}
d_{a t}= & d_{b t} \cdot\left\{R \cdot \frac{a_{a t}}{a_{b t}}+1-R\right\} \\
& \text { where } R=c_{14}+c_{15} \cdot h_{50}+c_{16} \cdot \sqrt{T g r}+c_{17} \cdot t
\end{aligned}
$$

Bij de analyse zijn alle opnamen uitgesloten waarbij er minder dan 4 bomen uit het proefperk waren verdwenen, omdat dit meestal geen dunning maar sterfte betreft. Ook opnamen waarbij de diameter voor dunning hoger was dan die na dunning zijn uitgesloten, omdat dit geen normale laagdunning betreft. Door die selectie zijn er maar 18 waarnemingen beschikbaar en bleek model (15) niet schatbaar.

Daarom is het originele model van La Bastide \& Faber gefit:

$$
d_{a t}=d_{b t} \cdot\left\{c_{18} \cdot \frac{a_{a t}}{a_{b t}}+1-c_{18}\right\}
$$

Met een $R^{2}$ adj van 0.956 werd voor de parameter gevonden $c_{18}=0.2418$ in een $95 \%$ betrouwbaarheidsinterval $\{0.118 ; 0.366\}$. 


\section{Constructie opbrengsttabellen}

Met de in deze studie gevonden relaties zullen nu nieuwe opbrengsttabellen worden gemaakt met verschillende dunninggraden.

Al eerder is besloten een indeling in relatieve boniteiten te maken, met daaraan gekoppeld de "hoogte" op 50 jaar. Er is gekozen voor de volgende presentatie van gegevens op dezelfde wijze als voor de douglas door Jansen et al. (2016). Er zijn echter geen data beschikbaar om de dominante hoogte en dominante diameter te bepalen, dus deze gegevens komen niet meer voor in deze opbrengsttabellen.

Voor een groot aantal van deze gegevens kunnen de gevonden relaties in de voorafgaande hoofdstukken worden gebruikt. Maar er zullen nog wat allometrische relaties gefit moeten worden, voor variabelen die tot nu toe nog niet voorkwamen.

\subsection{Overige allometrische relaties}

\section{Gemiddelde opstandhoogte}

Jansen et al. (2016) vonden voor de gemiddelde hoogte $\left(h_{g}\right)$ na dunning een powerfunctie gevonden met in de loop van de ontwikkeling wijzigende parameters:

$$
\begin{aligned}
& h_{a t}= \begin{cases}h_{a t(2)} & \text { for } h_{\text {top }} \leq 1.30 \mathrm{~m} \\
h_{a t(2)} & \text { for } h_{a t(1)} \leq h_{a t(2)} \\
h_{a t(1)} & \text { else }\end{cases} \\
& \text { where } h_{a t(1)}=\left(c_{19}+c_{20} \cdot a g e\right) \cdot h_{\text {top }}^{\left(c_{21}-c_{22} \cdot h_{\text {top }}\right)} \\
& h_{a t(2)}=c_{23} \cdot h_{\text {top }} \text { and } c_{23}=0.8 \text { (a set value) }
\end{aligned}
$$

Met een $R^{2}$ adj van 0.964 werden de volgende parameters gevonden: $c_{19}=1.1266, c_{20}=$ $0.0003495, c_{21}=0.8383$ en $c_{22}=-0.004244$. De begrenzing met de $c_{23}$ parameter is achteraf ingesteld omdat de basisformule voor lage leeftijden onrealistische waarden opleverde. Voor de hoogte voor dunning volgde:

$$
h_{b t}=c_{24} \cdot h_{a t} \quad \text { with } R^{2} \text { adj }=0.995 \text { and } c_{24}=0.9929
$$

\section{Opstandvolume}

In de data zijn de boomvolumes bepaald met de Formule (19) voor berk zijn de constanten van Schoonderwoerd et al. (1991) zijn gebruikt. Ze gebruikten het Schumacher-Hall-model (1933):

$$
v=d^{c_{25}} \cdot h^{c_{26}} \cdot e^{c_{27}} \text { met } d \text { in } \mathrm{cm}, h \text { in } \mathrm{m} \text { en } v \text { in } \mathrm{dm}^{3}
$$

Voor berk geldt: $c_{25}=1.54291, c_{26}=1.24235$ en $c_{27}=-2.66506$

Formule (19) is niet geschikt om het opstandvolume te bepalen. In het verleden werd gebruik gemaakt van de gemodificeerde opstandvolumefunctie van Heisterkamp (1981), de functie luidt: 


$$
\begin{aligned}
V= & c_{28} \cdot G^{c_{29}} \cdot h_{\text {top }}^{\left(c_{30}+c_{31} \cdot t_{0}\right)} \text { with } G \text { in } \mathrm{m}^{2} / \text { ha, } h_{\text {top }} \text { in } \mathrm{m} \text { and } V \text { in } \mathrm{m}^{3} / \text { ha } \\
& \text { where } t_{0}=t-t_{1.30}
\end{aligned}
$$

Met een $R^{2}$ adj van 0.980 werden de volgende parameters gevonden: $c_{28}=0.8452, c_{29}=$ $0.9553, c_{30}=0.7922$ en $c_{31}=0$ (niet significant) .

De formule van Heisterkamp is ontwikkeld voor opbrengsttabellen die een startwaarde hadden voor de opperhoogte, voor berk was die $7 \mathrm{~m}$. Daar beneden moet met de Formule (19) worden gewerkt.

\section{Beginstamtal}

Als beginstamtal is gekozen voor $5000\left(=c_{32}\right)$.

\section{Grenswaarde}

De steeds terugkerende grenswaarde voor de opperhoogte van $7 \mathrm{~m}$ is de parameter $c_{33}$ in de modellen. En geeft daarbij de boven grens aan voor de jeugdgroei.

\subsection{Opbrengsttabellen}

Allereerst is gekozen welke tabellen gepubliceerd zullen worden. Er is gekozen voor een opbrengsttabel voor Nederland met één dunninggraad en vijf boniteiten.

In Tabel 4 is de verdeling over boniteiten en leeftijdsklassen gegeven voor het aantal opstanden in de $4^{\mathrm{e}}$ Bosstatistiek met een leeftijd vanaf 11 jaar in Nederland. Dit geeft de behoefte aan tabellen weer, terwijl Tabel 10 een indicatie van de mogelijkheden geeft.

Tabel 10. Leeftijdsinterval in dataset per dunninggraad en boniteit.

Table 10. Age interval in the data set by thinning grade and site class.

\begin{tabular}{|l|ccccc|}
\hline Dunninggraad & I & II & III & IV & V \\
\hline zonder dunning & $15-22$ & & $145-157$ & & \\
zwakke laagdunning & $25-35$ & $10-37$ & & & \\
matige laagdunning & $9-24$ & $12-35$ & $10-116$ & $50-70$ & \\
sterke laagdunning & & $12-62$ & $12-23$ & & \\
zeer sterke laagdunning & $60-72$ & $12-90$ & $36-46$ & $46-104$ & $58-71$ \\
open stand & $50-61$ & $10-45$ & $7-125$ & $35-48$ & $50-64$ \\
\hline
\end{tabular}

Extrapolatie buiten het waarnemingsmateriaal moet in principe beperkt worden maar is onvermijdelijk (zie Tabel 10), de maximale leeftijd is op 80 jaar gesteld.

De gemiddelde dunninggraad licht tussen sterk en extra sterk. Als dunninggraad is voor berk gekozen voor een sterke laagdunning, ondanks dat deze in data minder vaak voorkomt.

Jansen et al. (2016) geven voor de douglas hoe deze geconstrueerd wordt. Deze werkwijze is gevolgd, uiteraard met aanpassing voor afwijkende onderdelen. 
In Tabel 11 is een lijst met de geschatte parameters opgenomen.

Tabel 11. Lijst met alle parameters.

Table 11. List with all parameters.

\begin{tabular}{|l|rr|}
\hline Parameter & Formula number & Value \\
\hline$c_{1}$ & $(7)$ & 1.3197868 \\
$c_{2}$ & $(7)$ & 1065.6372072 \\
$c_{3}$ & $(7)$ & 16.4603389 \\
$c_{4}$ & $(10)$ & 0.7913983 \\
$c_{5}$ & $(10)$ & 5.7658959 \\
$c_{6}$ & & \\
$c_{7}$ & & \\
$c_{8}$ & $(12)$ & 1.3952287 \\
$c_{9}$ & $(12)$ & 0.0541752 \\
$c_{10}$ & $(12)$ & 19.4648395 \\
$c_{11}$ & $(12)$ & 0.5623588 \\
$c_{12}$ & $(12)$ & 0.4383531 \\
$c_{13}$ & $(13)$ & 0.0955607 \\
$c_{14}$ & $(15)$ & 0.2417788 \\
$c_{15}$ & $(15)$ & 0 \\
$c_{16}$ & $(15)$ & 0 \\
$c_{17}$ & $(15)$ & 0 \\
$c_{18}$ & $(16)$ & 0.2417788 \\
$c_{19}$ & $(17)$ & 1.1265511 \\
$c_{20}$ & $(17)$ & 0.0003495 \\
$c_{21}$ & $(17)$ & 0.8382756 \\
$c_{22}$ & $(17)$ & -0.0042439 \\
$c_{23}$ & $(17)$ & 0.8000000 \\
$c_{24}$ & $(18)$ & 0.9928645 \\
$c_{25}$ & $(19)$ & 1.5429100 \\
$c_{26}$ & $(19)$ & 1.2423500 \\
$c_{27}$ & $(19)$ & -2.6650600 \\
$c_{28}$ & $(20)$ & 0.8452046 \\
$c_{29}$ & $(20)$ & 0.9552705 \\
$c_{30}$ & $(20)$ & 0.7921849 \\
$c_{31}$ & $(20)$ & 0 \\
$c_{32}$ & $N_{0}$ & 5000 \\
$c_{33}$ & & 7 \\
\hline
\end{tabular}

In Paragraaf 6.3 worden enkele eigenschappen van de uiteindelijk tabellen vergeleken met andere opbrengsttabellen. In Bijlage 1 zijn de geproduceerde opbrengsttabellen weergegeven.

\subsection{Vergelijking met andere opbrengsttabellen}

Hierna zijn enkele andere opbrengsttabellen voor de berk in West-Europa vergeleken met het hier gevonden resultaat, dat betreffen de tabel van Schwappach (1903) voor Duitsland, de tabel van Lockow (1996) voor Duitsland, die van Hamilton \& Christie (1971) voor UK en die van Carbonnier (1962) voor Zweden. Voor Nederland is er een tabel van Jansen et al. (1996) beschikbaar, dit is een bewerking van de tabel van Braastad (1967) voor Noorwegen. 


\subsubsection{Hoogteontwikkeling}

Schwappach (1903) heeft twee boniteiten met een hoogteontwikkeling die onvergelijkbaar is met die van de nieuwe tabellen voor Nederland (zie Figuur 8).

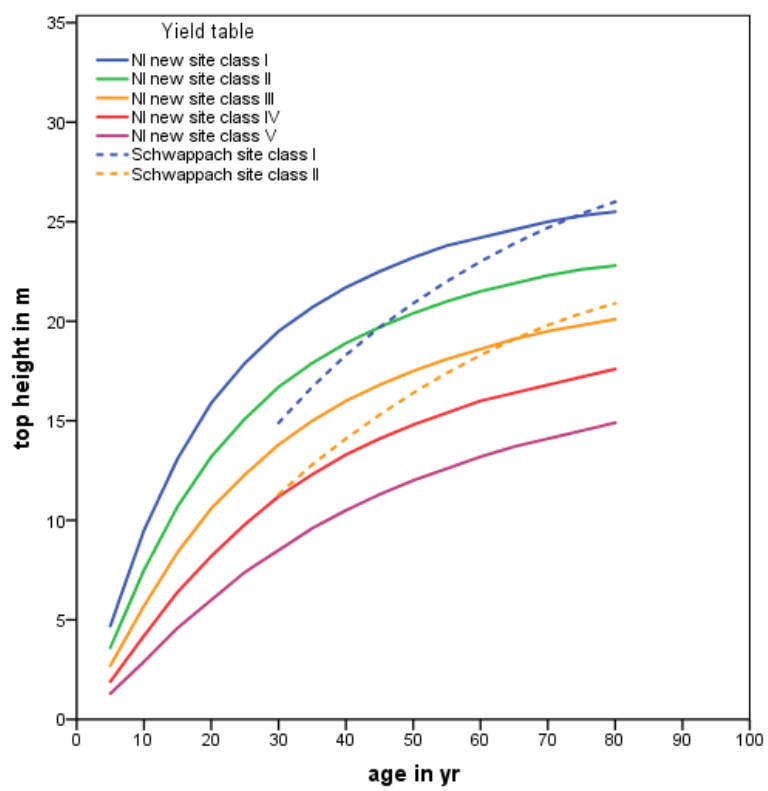

Figuur 8. Hoogteontwikkeling bij Schwappach en het nieuwe model voor Nederland.

Figure 8. Height development at Schwappach's site curves and the new model for Netherlands.

Lockow (1996) onderscheidt 5 boniteiten, waarvan boniteit IV goed overeenkomt met boniteit III van de nieuwe tabel voor Nederland, maar boniteit I loopt maar tot 25 jaar parallel aan die van de nieuwe tabel voor Nederland en de groei vlakt er veel later af (zie Figuur 9).

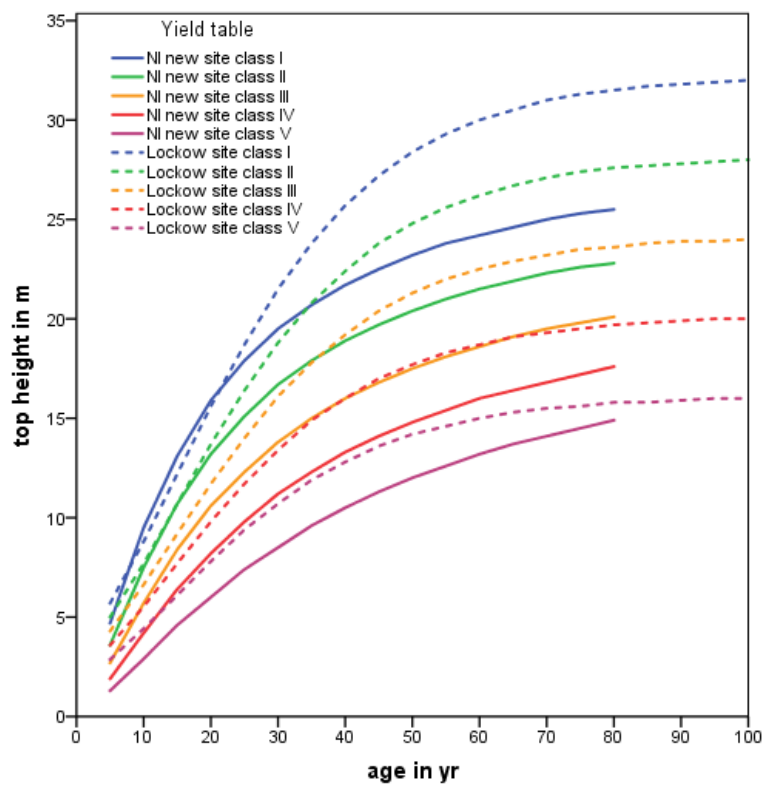

Figuur 9. Hoogteontwikkeling bij Lockow en het nieuwe model voor Nederland.

Figure 9. Height development at Lockow's site curves and the new model for Netherlands.

Jansen et al. (1996) onderscheiden 5 boniteiten. Er is grote overeenkomst met de tabel van Schwappach en geen enkele met de nieuwe tabel voor Nederland, zie Figuur 10. 


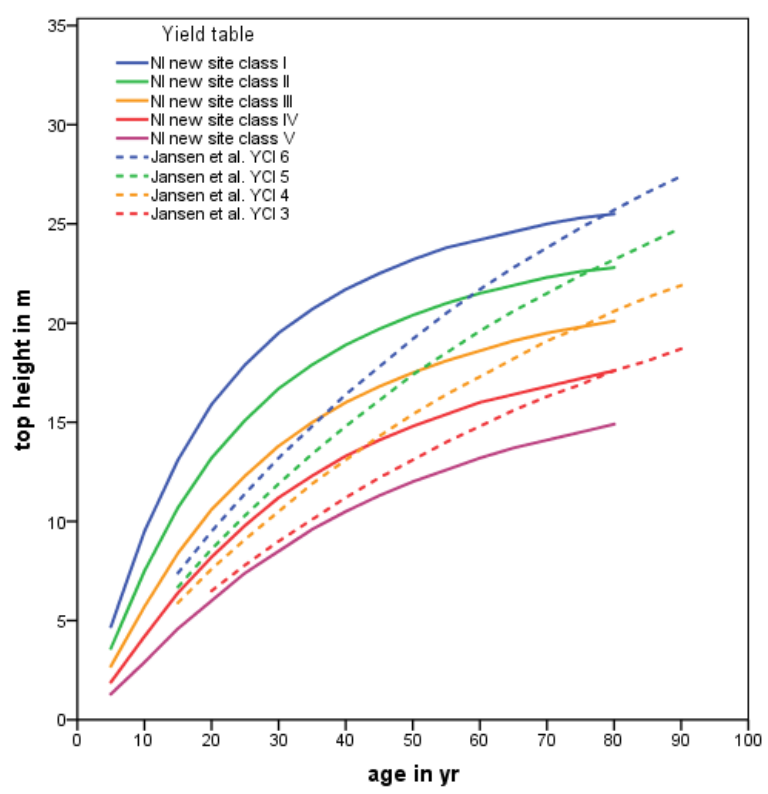

Figuur 10. Hoogteontwikkeling bij Jansen et al. en het nieuwe model voor Nederland.

Figure 10. Height development at Jansen's et al. site curves and the new model for Netherlands.

De bij hoogteontwikkeling bij Hamilton \& Christie (1971) vertoont een zeer goede overeenkomst met die van de nieuwe tabel voor Nederland (zie Figuur 11). Deze tabel is gemaakt voor zowel es, esdoorn als berk.

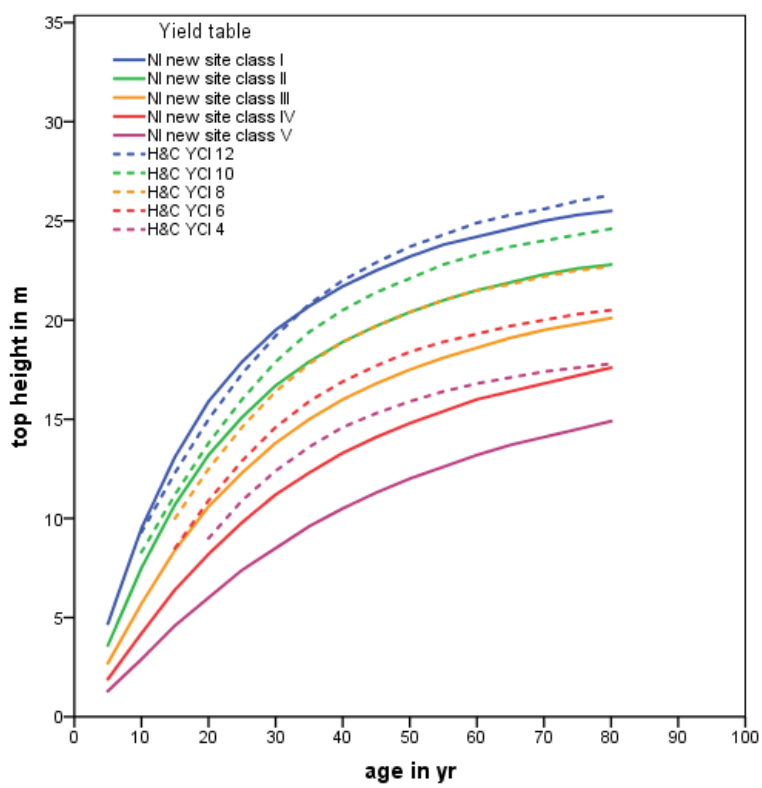

Figuur 11. Hoogteontwikkeling bij Hamilton \& Christie en het nieuwe model voor Nederland.

Figure 11. Height development at Hamilton \& Christie's site curves and the new model for Netherlands.

Carbonnier (1962) heeft één boniteit met een $h_{50}$ van $22 \mathrm{~m}$. Zijn hoogteontwikkeling komt totaal niet overeen met die van de nieuwe tabel voor Nederland (zie Figuur 12). 


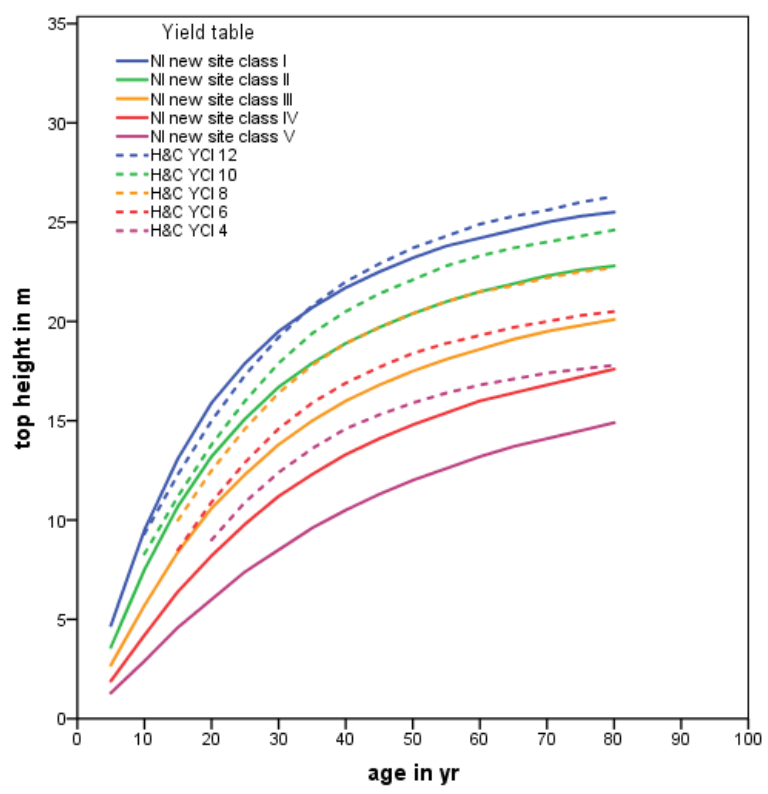

Figuur 12. Hoogteontwikkeling bij Carbonnier en het nieuwe model voor Nederland. Figure 12. Height development at Carbonnier's site curves and the new model for Netherlands.

Er blijken dus gemeenschappelijke punten met de nieuwe tabel voor Nederland bij Lockow en bij Hamilton \& Christie. Hier is sprake van het gedrag van een pioniersoort met een snelle jeugdgroei en afvlakking vanaf ongeveer 40 jaar en bij Lockow nog wat later, hierdoor wordt bij Lockow een ongeveer $6 \mathrm{~m}$ hogere maximale hoogte bereikt. Daarnaast zijn er drie andere tabellen (Schwappach, Carbonnier en Jansen et al.) waar sprake is van een bijna lineaire groei vanuit de oorsprong.

\subsubsection{Productieniveau}

Het productieniveau wordt bij voorkeur gemeten op basis van de gemiddelde volumebijgroei bij zekere leeftijd. Hier is echter naar de totale grondvlakproductie gekeken.

In Figuur 13 is de totale grondvlakproductie per opbrengsttabel uitgezet tegen de opperhoogte voor alle boniteiten. De meeste opbrengsttabellen hebben als startpunt een hoogte tussen 8 tot $13 \mathrm{~m}$, en de nieuwe tabel vanaf $1.3 \mathrm{~m}$.

Het productieniveau bij Lockow, Jansen et al. en Carbonnier komt redelijk overeen met dat van de nieuwe tabel. De hellingshoeken bij Schwappach komen redelijk overeen met die van de nieuwe tabel, maar het aanvangsniveau is stukken lager omdat daar informatie ontbreekt over vroege dunningen. De tabel van Hamilton \& Christie is gemaakt voor zowel es, esdoorn als berk en mist elke overeenkomst met de andere vergeleken tabellen. 


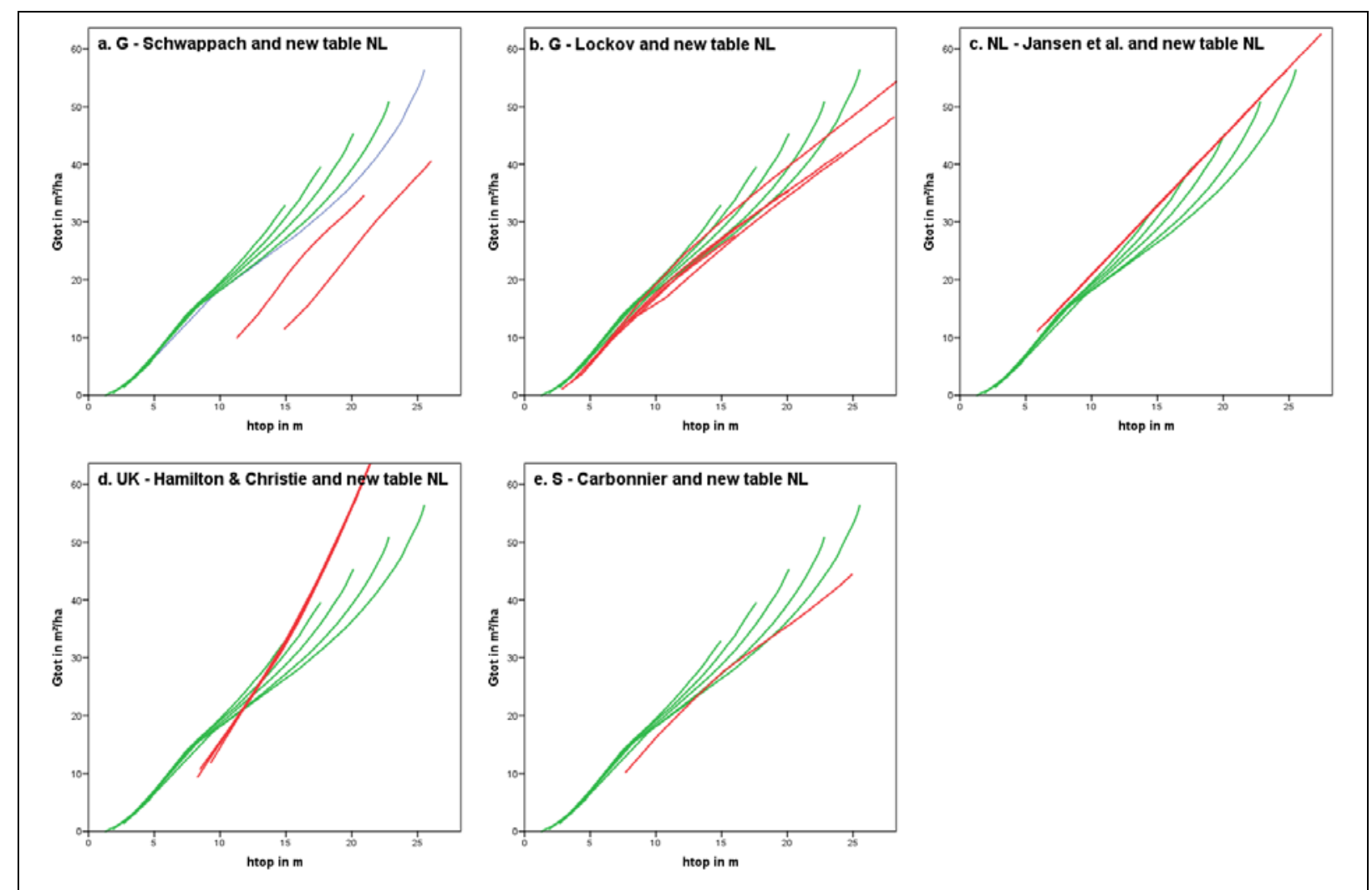

Figuur 13. De totale grondvlakproductie Gtot in relatie tot de opperhoogte bij de nieuwe tabel voor Nederland (in groen) in vergelijking met andere opbrengsttabellen (in rood) voor Schwappach (a), Lockow (b), Jansen et al. (c), Hamilton \& Christie (d) en Carbonnier (e).

Figure 13. Total basal area production Gtot and top height for the new yield table (in green) in comparison with other yield tables (in red) by Schwappach (a), Lockow (b), Jansen et al. (c), Hamilton \& Christie (d) en Carbonnier (e). 


\section{Discussie en conclusies}

\subsection{Hoogtegroei}

De hoogteontwikkeling van de opstand is een resultante van hoogtegroei en topsterfte. Een biologisch relevant groeimodel moet een buigpunt en een asymptoot hebben. Bij het schatten van de parameters van de verschillende modellen zijn naast de 43 plots van Figuur $1 a$ ook de 2683 opstanden van de 4 e Bosstatistiek (CBS, 1985) uit Figuur 1b gebruikt. Met de analysemethode die Jansen et al. (2018) voor de zwarte els gebruikten zijn 4 groepen in de data van de $4^{\mathrm{e}}$ Bosstatistiek onderscheiden die vervolgens als kunstmatige plots zijn behandeld. Een punt van zorg is feit dat die groepen niet onafhankelijk van het model zijn te bepalen. Dus ieder model genereert een eigen groepsindeling. Met een MCA zijn de resultaten van de analyses vergeleken en het model van Cieszewski (2001) is gekozen:

$$
h_{\text {top }}=h_{50} \cdot \frac{t^{c_{1}} \cdot\left(50^{c_{1}} \cdot R+c_{2}\right)}{50^{c_{1}} \cdot\left(t^{c_{1}} \cdot R+c_{2}\right)} \text {, where } R=Z+\sqrt{Z^{2}+\frac{2 \cdot c_{2} \cdot h_{50}}{50^{c_{1}}}} \text { and } Z=h_{50}-c_{3}
$$

Voor boniteren geldt dan:

$$
\rightarrow h_{50}=h_{\text {top }} \cdot \frac{50^{c_{1}} \cdot\left(t^{c_{1}} \cdot R+c_{2}\right)}{t^{c_{1}} \cdot\left(50^{c_{1}} \cdot R+c_{2}\right)} \text { and } S=h_{50} \cdot \frac{50^{c_{1}} \cdot R+c_{2}}{50^{c_{1}} \cdot R+c}
$$

De asymptoot, hier de site index $S$ genoemd, is een maat voor de geschiktheid van de standplaats (boniteit) voor de berk, in de praktijk wordt echter $h_{50}$ als maat voor de boniteit gebruikt. Boniteren is met dit model lastig, want vereenvoudigd staat in Formule (22) $h_{50}=f\left(h_{t o p}, t, h_{50}\right)$, je moet dus met een startwaarde voor $h_{50}$ werken en iteratief naar een oplossing werken.

De $R^{2}$ adj bleek met een waarde van 0.986 iets lager dan wat gemiddeld in de eerdere studies werd gevonden.

\subsection{Diameter en grondvlak}

In Paragraaf 4.2 is het model voor de lopende bijgroei van het grondvlak ontwikkeld. Dit model start na het bereiken van een opperhoogte van $7 \mathrm{~m}$. In Paragraaf 7.2.2 wordt hierop ingegaan. Om een startwaarde voor de diameter voor dunning en het grondvlak per ha voor dunning te hebben op het tijdstip $t_{7}$ is in Paragraaf 4.1 een model ontwikkeld voor de diameterontwikkeling. In Paragraaf 7.2.1 wordt dit besproken.

\subsubsection{Diameterontwikkeling}

In Paragraaf 4.1 is zijn twee modellen voor de diameterontwikkeling gebruikt, één voor de data in de $4^{\mathrm{e}}$ Bosstatistiek en één voor de data uit de proefperken. De resultaten liepen ver uiteen, besloten is met een gemiddelde te werken: 


$$
d_{b t}=f_{2}\left(h_{t o p}, d_{7}\right) \text { for } h_{t o p} \leq 7
$$

where $d_{7}$ (the diameter at a height of $7 \mathrm{~m}$ ) is an estimated parmeter

Voor $d_{7}$ werd een waarde van $5.8 \mathrm{~cm}$ gevonden voor $N_{0}=5000$. Vergelijking met andere opbrengsttabellen is niet mogelijk.

\subsubsection{Grondvlakbijgroei}

In Paragraaf 4.2 werd Formule (12) voor de grondvlakbijgroei gevonden, in vereenvoudigde vorm luidt dit:

$$
\begin{aligned}
i_{G, i j k}= & f_{1}(S \%) \cdot f_{2}\left(h_{50}\right) \cdot\left\{\frac{F_{3}\left(h_{2}, t_{2}\right)-F_{3}\left(h_{1}, t_{1}\right)}{t_{2}-t_{1}}\right\} \\
& \text { for the } j^{\text {th }} \text { plot at age } i=t_{m}=\left(t_{1}+t_{2}\right) / 2 \text { in the } k^{\text {th }} \text { year of recording }
\end{aligned}
$$

Een power-functie voor $F_{3}$ het meest geschikt. Net als bij de douglas (Jansen et al. 2016) stijgt de grondvlakbijgroei met toenemende boniteit, de stijging is alleen een gevolg van $F_{3}$ maar ook van $f_{2}$. De correctiefactor voor de grondvlakbijgroei $f_{1}$ is actief vanaf een $S \%$ van ongeveer 19.5. De $R^{2}$ adj is met 0.615 vrij hoog. Deze grondvlakbijgroei komt redelijk overeen met die Jansen et al. (1996) en Carbonnier (1962), maar wijkt sterk af van die bij Schwappach (1903) en Hamilton \& Christie (1971). Bij Lockow (1996) is de grondvlakbijgroei over de hele omloop ongeveer gelijk, maar verschilt per boniteit.

\subsection{Dunning}

Om de dunning te kwantificeren is een dunninggraad gebruikt. De in Duitsland gebruikelijke indeling met een A- tot en met D-graad gebaseerd op het dunnen van bomen behorend tot een of meerdere Kraftse boomklassen is in Nederland nooit aangeslagen. Becking (1953) vindt deze methode te weinig kwantitatief en kiest voor een $S \%$ (volgens Hart, 1928) van 16 $\%$ voor een zwakke laagdunning, met $3 \%$ erbij is dan sprake van de volgende dunninggraad, namelijk bij $19 \%$ een matige laagdunning. In Tabel 8 is een volledig overzicht van het $S \%$ en de bijbehorende namen. In andere opbrengsttabellen is een geleidelijk toename een bepaald $S \%$ te zien vanaf ongeveer 50 jaar. Dit is logisch omdat op latere leeftijd de kroonvorm verandert, waardoor bij gelijkblijvende standruimte een hogere $S \%$ nodig is. De mate van deze verandering kon niet geschat worden en de gemiddelde waarde van drie vergeleken opbrengsttabellen is in Formule (13) weergegeven. Het ratiomodel (15) van La Bastide en Faber (1972) is gebruikt waarbij de ratio een constante factor is.

\subsection{Kwaliteit van het model}

In Tabel 12 is de groeiklasse per boniteit aangegeven. Deze groeiklasse is het totaal geproduceerde (en deels geoogste) gemiddelde spilhoutvolume in $\mathrm{m}^{3} \mathrm{ha}^{-1} \mathrm{jr}^{-1} \mathrm{bij}$ een leeftijd van 50 jaar. De nieuwe tabel past binnen de range van de vergeleken tabellen, maar is weinig eenduidigheid. 
Tabel 12. Groeiklasse per opbrengsttabel en boniteit.

Table 12. Yield class (mean annual volume increment at $50 \mathrm{yr}$.) per yield table and site class.

\begin{tabular}{|c|c|c|c|c|c|c|}
\hline \multirow{2}{*}{ Yield table } & \multirow{2}{*}{ Thinning grade } & \multicolumn{5}{|c|}{ site class } \\
\hline & & I & II & III & IV & V \\
\hline New table Netherlands & heavy & 6.3 & 5.2 & 4.1 & 3.2 & 2.3 \\
\hline Lockov, 1996 & heavy & 10.9 & 8.7 & 6.7 & 5.0 & 3.4 \\
\hline Schwappach, 1903 & extra heavy & 4.6 & 3.4 & & & \\
\hline Jansen et al . 1996 & extra heavy & 5.9 & 4.9 & 3.9 & 2.9 & \\
\hline Carbonnier, 1962 & extra heavy & 4.9 & & & & \\
\hline Hamilton \& Christie, 1971 & open stand & 11.7 & 9.8 & 7.9 & 6.0 & 4.0 \\
\hline
\end{tabular}

In Tabel 3 blijkt dat het totale bereik voor de $h_{50} 10.6$ tot $24.6 \mathrm{~m}$ bedraagt voor de boniteiten I tot $\mathrm{V}$. De hoogst geschatte $h_{50}$ bij de data van de $4^{\mathrm{e}}$ Bosstatistiek bedroeg $28.3 \mathrm{~m}$, de daarbij behorende $S$-waarde zou dan maximaal $33.4 \mathrm{~m}$ bedragen.

Volgens https://www.monumentaltrees.com/nl/hoogterecords/nld/ (geraadpleegd 10-122017) staat de hoogste berk (37.5 m met een leeftijd van ca 150 jaar) van Nederland in Bronbeek te Arnhem. De $h_{50}$ van een opstand met gelijke hoogte en leeftijd zou dan $34.4 \mathrm{~m}$ moet zijn. In de data van het onderzoek komt zo'n hoogte niet voor en ook in de $4^{\mathrm{e}}$ bosstatistiek is de maximale opstandhoogte beduidend lager $(27 \mathrm{~m})$. De kans dat er standplaatsen in $\mathrm{Ne}-$ derland zijn waar het groeimodel niet toepasbaar is lijkt daarom onwaarschijnlijk, wel zijn er standplaatsen met een betere boniteit dan de $\mathrm{I}^{\mathrm{e}}$. 


\section{Samenvatting}

Dit is een rapport over de groei en productie van de ruwe berk (Betula pendula) in Nederland. Er is onderzocht hoe de ontwikkeling van de hoogte, diameter en het grondvlak in de tijd is geweest en hoe deze beïnvloed wordt door de dunning. Met de gevonden relaties en andere allometrische relaties is een opbrengsttabel opgesteld met één dunninggraad.

De gebruikte dataset betreft de gegevens die tussen 1982 en 1994 in Nederland in groei- en productieonderzoek bij de ruwe berk zijn verzameld door voormalige Dorschkamp/IBN; dit omvat 10 proefperken met 21 opnamen. Daarnaast zijn 33 plots met 111 opnamen uit de $4^{e}$ Bosstatistiek/HOSP gebruikt, en de hoogteschattingen in 2683 berkenbossen uit de $4^{\mathrm{e}}$ Bosstatistiek. Per opname zijn leeftijd, opnamedatum en opperhoogte bekend en per toestand voor, na en van de dunning stamtal, grondvlak, diameter, hoogte en volume.

De hoogteontwikkeling is onderzocht met vier bekende groeimodellen en bleek het best te verklaren met het model van Cieszewski (2001), dit heteromorfe model luidt als volgt:

$h_{\text {top }}=h_{50} \cdot\left\{t^{c_{1}} \cdot\left(50^{c_{1}} \cdot R+c_{2}\right)\right\} /\left\{50^{c_{1}} \cdot\left(t^{c_{1}} \cdot R+c_{2}\right)\right\}$ met $R=Z+\sqrt{Z^{2}+2 \cdot c_{2} \cdot h_{70} / 50^{c_{1}}}$ en $Z=h_{50}-c_{3}$. Hierin is $h_{50}$ een proefperkspecifieke parameter en maat voor een absolute hoogteboniteit, $c_{1}, c_{2}$ en $c_{3}$ soortspecifieke parameters die de vorm van de curve bepalen. De $R^{2}$ adj bleek met 0.986 hetgeen gemiddeld is voor een hoogtegroeimodel. De hoogteontwikkeling bij de opbrengsttabel van Hamilton \& Christie (1971) voor Groot-Brittannië en bij Lockow (1996) voor Duitsland vertoont gelijkenis met het nieuwe model voor Nederland. De hoogteontwikkeling bij de opbrengsttabellen van Schwappach (1903) voor Duitsland, die van Carbonnier (1962) voor Zweden en Jansen et al. (1996) voor Nederland wijken erg af van het nieuwe model voor Nederland.

De diameterontwikkeling tot een hoogte van $7 \mathrm{~m}$. werd het best verklaard met het model van Jansen et al. (2016) $d_{b t}=d_{7} \cdot f\left(h_{\text {top }}\right)$. Met 637 data van de $4^{\mathrm{e}}$ Bosstatistiek werd met $R^{2}$ adj $=0.565$ en $d_{7}=6.9 \mathrm{~cm}$ een nogal afwijkend resultaat gehaald ten opzichte van de permanente proefperken $n=21, R_{a d j}^{2}=0.704$ en $d_{7}=4.6 \mathrm{~cm}$ bij $N_{0}=5000$. Hiervan is het gemiddelde aangehouden. Voor het traject boven een hoogte van $7 \mathrm{~m}$ is de grondvlakbijgroei gemodelleerd met het model van Jansen et al. (2016): $i_{G}=f\left(h_{50}, h_{\text {top }}\right.$, age $\left., S \%, y r\right)$ waarbij gebruik gemaakt is van een powermodel. Voor $S \%>19.5$ daalt de grondvlakbijgroei niet-lineair met gemiddeld $2.3 \%$ per eenheid $S \%$ verschil. De $R^{2}$ adj is 0.595 . Het jaar van opname (yor) bleek niet significant. Het model is in strijd met de wet van Eichhorn. Het effect van de dunning op de diameter na dunning $\left(d_{a t}\right)$ is gemodelleerd met het La Bastide-Faber model (1972).

Met de geïntegreerde modellen is een opbrengsttabel gemaakt voor een leeftijd tot 80 jaar met 5 boniteiten en een matige laagdunning. Deze zijn vergeleken met de tabellen van Schwappach (1903) en van Lockow (1996) voor Duitsland, Jansen et al. (1996) voor Nederland, Carbonnier (1962) voor Zweden en die van Hamilton \& Christie (1971) voor UK. Bij de vergelijking bleek de relatie tussen de totale grondvlakproductie en de hoogte bij de nieuwe tabel voor Nederland overeenkomst te hebben met die van de tabellen van Lockow, Jansen et al. en Carbonnier. Er bleken grote verschillen in groeiklasse (gemiddelde volumebijgroei bij 50 jaar) tussen de verschillende opbrengsttabel. De nieuwe tabel ligt wel binnen de range van de vergeleken tabellen. Op hoofdlijnen bleek het model van Jansen et al. (2016) voor de douglas ook bruikbaar voor de berk. 


\section{Summary}

This report describes growth and yield of silver birch (Betula pendula) in Netherlands. The report describes the development of height, diameter and basal area over time, based on permanent field plots, and the effect of thinning on these characteristics. The regularities and allometric relationships found were used to construct a yield table for even-aged stands of silver birch.

The dataset used in this study is composed of all growth and yield related research on silver birch in the Netherlands, carried out between 1982 and 1994 by the former Dorschkamp/IBN research institute, and includes 10 experimental plots. Furthermore, 33 sample plots from the 4th Dutch National Forest Inventory and from the timber prognosis system HOSP, were used. In total, the dataset consists of 43 plots with 132 recordings. Height recordings in 2683 silver birch stands from the 4th Dutch National Forest Inventory were also used. Each plot record includes age, recording date and top height, as well as stem density, basal area, diameter, height and volume before and after thinning and of the thinning itself.

Height development was analysed using four well-known equations, and the best fit was found with Cieszewski's model (2001); this polymorphic model is given by:

$h_{\text {top }}=h_{50} \cdot\left\{t^{c_{1}} \cdot\left(50^{c_{1}} \cdot R+c_{2}\right)\right\} /\left\{50^{c_{1}} \cdot\left(t^{c_{1}} \cdot R+c_{2}\right)\right\}$ where $R=Z+\sqrt{Z^{2}+2 \cdot c_{2} \cdot h_{50} / 50^{c_{1}}}$ and $Z=h_{50}-c_{3}$. Here, $h_{50}$ is a plot specific parameter and a measure for site index, and $c_{1}, c_{2}$ and $c_{3}$ are species-specific parameters that determine the shape of the curve. With conditionally non-linear regression (CNLR) a solution was found with an $R^{2}$ adj of 0.986 .

The height development was compared with the models Hamilton \& Christie (1971) for the UK, Schwappach (1903) and Lockow (1996) for Germany, Carbonnier (1962) for Sweden and Jansen et al. (1996) for the Netherlands. There was a reasonable match with Hamilton \& Christie's and with Lockow's height development models, but a mismatch with all other models.

The diameter development (before thinning: $d_{b t}$ ) to a height of $7 \mathrm{~m}$ was described by the model of Jansen et al. (2016) $d_{b t}=d_{7} \cdot f_{1}\left(h_{\text {top }}\right)$ where $d_{7}=f_{2}\left(N_{0}\right)$. With the permanent plots, with 21 recordings, and $R^{2}$ adj $=0.704$, a value of 5.8 was found for $d_{7}$, for $N_{0}=5000$. But with 637 recordings of the Fourth Dutch National Forest Inventory and in this case an $R^{2} \mathrm{adj}=$ $0.565, d_{7}$ was equal to $6.9 \mathrm{~cm}$. The average of both values was chosen for the yield table construction. The model was only used for diameter and basal area development up to a height of $7 \mathrm{~m}$. For the development above $7 \mathrm{~m}$, basal area increment was described using the model of Jansen et al (2016): $i_{G}=f\left(h_{50}, h_{\text {top }}, t, S \%\right.$, yor $)$, using a power function. For the Becking-Hart spacing index $S \%$ larger than 19.5 , basal area increment decreased nonlinearly with $S \%$, with an average value of $2.3 \%$ per unit $S \%$. The $R^{2}$ adj was 0.595 . The year of recording (yor) was not significant, and the model does not follow Eichhorn's law. The effect of thinning on diameter after thinning $\left(d_{a t}\right)$ was modelled with La Bastide \& Faber's model (1972).

Using the integrated models, a yield table was created for even-aged stands of ages up to 80 years, using five site classes. The yield table was compared with tables from Sweden, Germany and the UK. The production level of all these tables showed considerable variation, and the growth level of the new table for the Netherlands was within the range of values reported elsewhere. Overall, the model of Jansen et al. (2016) for Douglas fir turned out to be suitable also for silver birch. 


\section{Literatuur}

Bartelink, H.H., A.F.M. Olsthoorn, A. Oosterbaan \& S.M.J. Wijdeven, 2001. Overzicht van een eeuw onderzoek naar groei en opstandsontwikkeling in relatie tot groeiplaats en beheer. Alterra, Research Instituut voor de Groene Ruimte, Wageningen, Alterrarapport 256.

Becking, J. H., 1953. Thinning research in forestry. Netherlands Journal of Agricultural Science; 1953. 1(2):122-9.

Braastad, H., 1967. Produksjonstabeller for bjørk. Meddelelser fra Det Norske Skog-fors $\varnothing$ ksveren 22 (84), 265-365.

Burkhart, H,E. \& R.B. Tennent, 1977. Site index equations for radiata pine in New Zealand. New Zealand Journal of Forestry Science 7: 408416.

Carbonnier C., 1962. Utvecklingen av metodiken vid tillvätprognoser för skogsbestånd och en produkttionstabell för vårtbjörk. Svenskt Jordbruk och Skogbruk 1962: 514-520.

C.B.S. (Centraal Bureau voor de Statistiek),1985. De Nederlandse Bosstatistiek, deel 1: de oppervlakte bos,1980 1983. Staatsuitgeverij, s'Gravenhage

Cieszewski C.J., 2001. Three methods of deriving advanced dynamic site equations demonstrated on inland Douglas-fir site curves. Can. J. For. Res. 31: 165-173 .

Hamilton, G.J. and J.M. Christie, 1971. Forest management tables (metric). Forestry Commission Booklet no. 34. HMSO, London.

Hart, H.M.J., 1928. Stamtal en dunning : een orienteerend onderzoek naar de beste plantwijdte en dunningswijze voor den djati. Proefschrift Wageningen. Mededeelingen Proefstation voor het Boschwezen (21) 219 p. + 7 bijl. Veenman, Wageningen.

Heisterkamp, S.H., 1981. Opstandsinhoudsfuncties. Rapport Rijksinstituut voor onderzoek in de bos- en landschapsbouw "De Dorschkamp" 271, Wageningen.

IUFRO, 1959. The standardization of symbols in forest mensuration. International Union of Forest Research Organizations, Londen.

Jansen, J.J. \& J.W. Hildebrand, 1986. Een nieuwe opbrengsttabel voor de fijnspar (Picea abies Karst.) in Nederland. Landbouwhogeschool, Vakgroep Boshuishoudkunde, Wageningen.

Jansen, J.J., J. Sevenster \& P.G. Faber (redactie), 1996. Opbrengsttabellen voor belangrijke boomsoorten in Nederland. IBN rapport 96/Hinkeloord reports No.17, 202 pag.

Jansen, J.J., H. Schoonderwoerd, G.M.J. Mohren \& J. den Ouden, 2016. Groei en productie van douglas in Nederland. Becking's dunningproeven ontsloten. Wageningen Academic Publishers.

Jansen, J.J., A. Oosterbaan, G.M.J. Mohren \& J. den Ouden, 2018. Groei en productie van zwarte els in Nederland. Wageningen Universiy, in prep.

La Bastide, J.G.A. \& P.J. Faber, 1972. Revised yield tables for six tree species in the Netherlands. Uitvoerig Verslag Bosbouwproefstation "De Dorschkamp", band 11, nr. 1.

Lockow, K.-W., 1996. Ertragstafel für die Sandbirken (Betula pendula Roth) in MecklenburgVorpommern. Forstliche Forschungsanstalt Eberswalde, Fachgebiet Waldwachstum.

Oldenburger, J.F., J.J. Jansen, A. Oosterbaan, H. Lu, G.M. Mohren \& J. den Ouden, 2016. FEM growth and yield data Monocultures - Silver birch. DANS: http://dx.doi.org/10.17026/dans-zth-5df8.

Oosterbaan A. en H. Polman, 2007. Meer met berk. Vakblad NBL 4 (2007) 9 p.24-27.

Pienaar, L.V., \& K.J. Turnbull, 1973. The Chapman-Richards generalization of von Bertallanffy's growth model for basal area growth and yield in even-aged stands. Forest Science 19: 2-22. 
Schober, R., 1987. Ertragstafeln wichtiger Baumarten. Dritte Auflage, J.D. Sauerländer's Verlag, Frankfurt a. M.

Schoonderwoerd, H., J.P.G. de Klein en J.N. van de Schee, 1991. Massatabellen voor berk, beuk, es en inlandse eik (bosbomen). Maatschappij Damen, Schoonderwoerd en de Klein, Rapport nr. 23.

Schumacher, F.X. \& Hall, F.S., 1933. Logarithmic expression of timber-tree volume. Journal of Agricultural Research, v.47, n.9, p.719-734.

Schwappach, A., 1903. Beitrage zur Kenntnis der Wuchsleistung von Birkenbeständen.

Zeitschr für Forst- und Jagdwesen Berlin: 479-484. In: Schober, R., 1987. Ertragstafeln wichtiger Baumarten. Dritte Auflage, J.D. Sauerländer's Verlag, Frankfurt a. M. 


\section{Bijlage 1. Opbrengsttabel voor ruwe berk Nederland 2018}

\section{Toelichting opbrengsttabellen}

In de kop van de opbrengsttabellen zijn een aantal standaard symbolen (IUFRO, 1959). In onderstaande tabel wordt de SI-eenheid vermeld en de betekenis van het symbool weergegeven.

\begin{tabular}{|c|c|c|}
\hline symbool & eenheid & betekenis \\
\hline Boniteit & & relatieve indeling in groeiklassen \\
\hline$h_{50}$ & $\mathrm{~m}$ & Site index (opperhoogte op 50 jr.) \\
\hline$P 50$ & $m^{3} h a^{-1} j^{-1}$ & Productieklasse op 50 jr. ${ }^{1)}$ \\
\hline$t$ & j & leeftijd vanaf kieming \\
\hline$h_{\text {top }}$ & $\mathrm{m}$ & opperhoogte \\
\hline$N$ & ha-1 & stamtal per ha \\
\hline$S \%$ & & Hart-Becking dunning-index \\
\hline G & $\mathrm{m}^{2} \mathrm{ha}^{-1}$ & grondvlak per ha \\
\hline$d_{g}$ & $\mathrm{~cm}$ & diameter $(1,30 \mathrm{~m})$ van de middenboom ${ }^{2)}$ \\
\hline$h_{g}$ & $\mathrm{~m}$ & hoogte van de middenboom \\
\hline$V$ & $m^{3} h a^{-1}$ & volume per ha ${ }^{3)}$ \\
\hline$I c_{G}$ & $m^{2} h a^{-1} j^{-1}$ & lopende grondvlakbijgroei per ha per jaar op leeftijd $t$ jaar \\
\hline$I c_{V}$ & $m^{2} h a^{-1} j^{-1}$ & lopende volumebijgroei per ha per jaar op leeftijd $t$ jaar \\
\hline $\operatorname{Im} m_{G}$ & $m^{3} h a^{-1} j^{-1}$ & gemiddelde grondvlakbijgroei per ha per jaar tot op leeftijd $t$ jaar \\
\hline $\operatorname{Im} V$ & $m^{3} h a^{-1} j^{-1}$ & gemiddelde volumebijgroei per ha per jaar tot op leeftijd $t$ jaar \\
\hline
\end{tabular}

1) gemiddelde productie, inclusief dunning maar exclusief sterfte (volumebijgroei) per ha tot op leeftijd 50 jaar

2) boom met gemiddeld boomgrondvlak en boomvolume

3) Het volume is gedefinieerd als het spilhoutvolume met schors. 


\section{Explanation yield tables}

In the header of the yield tables a number of standard symbols (IUFRO, 1959) are used. In the table below the SI units and the meaning of the symbols are given.

\begin{tabular}{|c|c|c|}
\hline symbol & unit & meaning \\
\hline Site class & & relative partition in site classes \\
\hline$h_{50}$ & $\mathrm{~m}$ & Site index (top height at $50 \mathrm{yr}$.) \\
\hline$P 50$ & $\mathrm{~m}^{3} \mathrm{ha}^{-1} \mathrm{yr}^{-1}$ & Production class at $50 \mathrm{yr}{ }^{1)}$ \\
\hline$t$ & j & age since germination \\
\hline$h_{\text {top }}$ & $\mathrm{m}$ & top height \\
\hline$N$ & $h a^{-1}$ & Number of stems per ha \\
\hline S\% & & S\% (Hart-Becking spacing index) \\
\hline G & $m^{2} h a^{-1}$ & Basal area per ha \\
\hline$d_{g}$ & $\mathrm{~cm}$ & diameter $(1,30 \mathrm{~m})$ of the basal area mean tree \\
\hline$h_{g}$ & $\mathrm{~m}$ & height of the basal area mean tree \\
\hline$V$ & $m^{3} h a^{-1}$ & volume per ha ${ }^{2)}$ \\
\hline$I c_{G}$ & $\mathrm{~m}^{2} \mathrm{ha} \mathrm{a}^{-1} \mathrm{yr}^{-1}$ & current basal area increment per ha per year at age $t$ \\
\hline$I c_{V}$ & $m^{2} \mathrm{ha}^{-1} \mathrm{yr}^{-1}$ & current volume increment per ha per year at age $t$ \\
\hline$I_{G}$ & $\mathrm{~m}^{3} \mathrm{ha}^{-1} \mathrm{yr}^{-1}$ & mean basal area increment per ha per year until age $t$ \\
\hline $\operatorname{Im}_{V}$ & $\mathrm{~m}^{3} \mathrm{ha}^{-1} \mathrm{yr}^{-1}$ & mean volume increment per ha per year until age $t$ \\
\hline
\end{tabular}

1) Mean production, including thinning but excluding mortality (volume increment) per ha until age $50 \mathrm{yr}$.

2) The volume is defined as the stem volume over bark. 


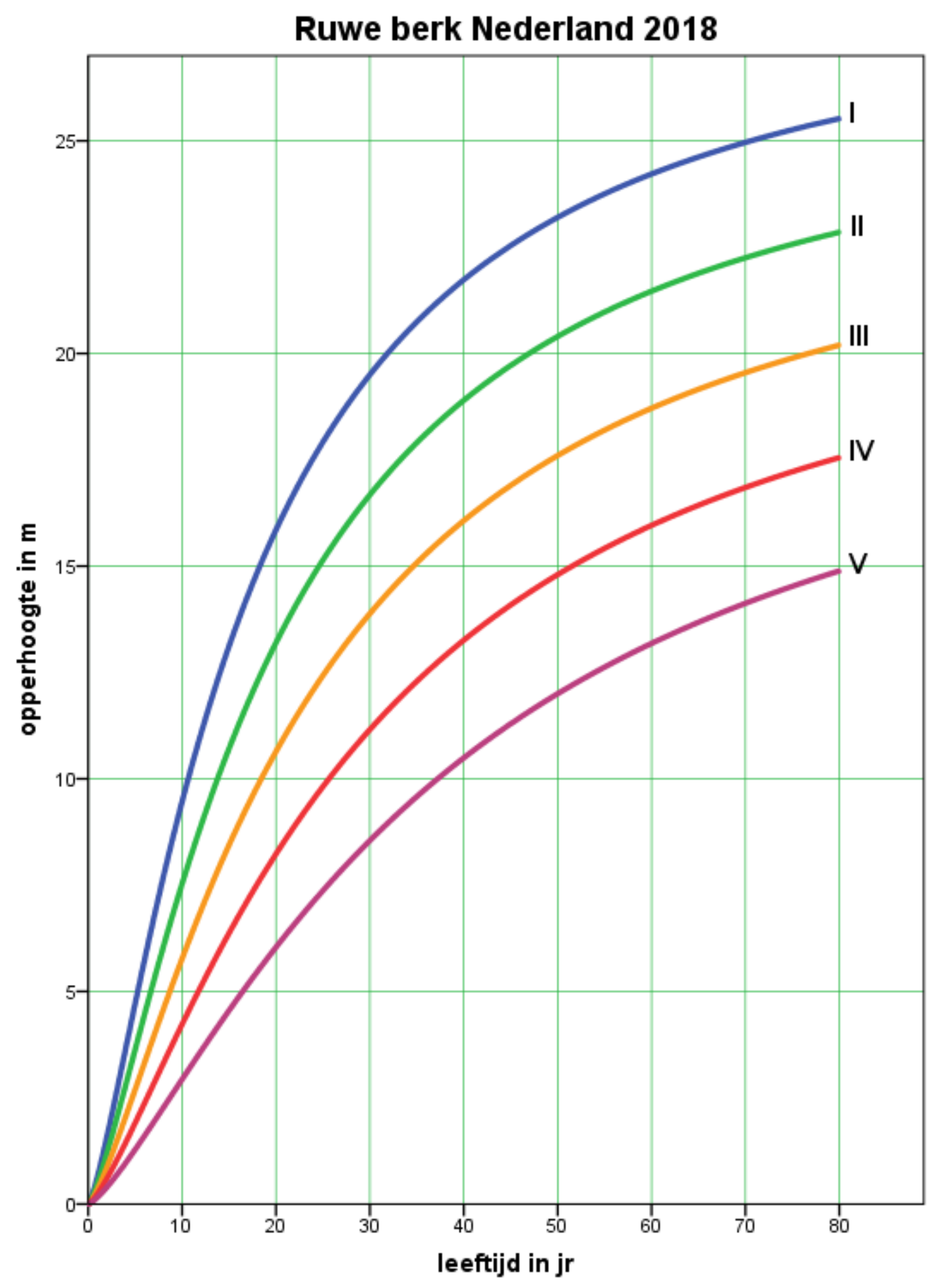




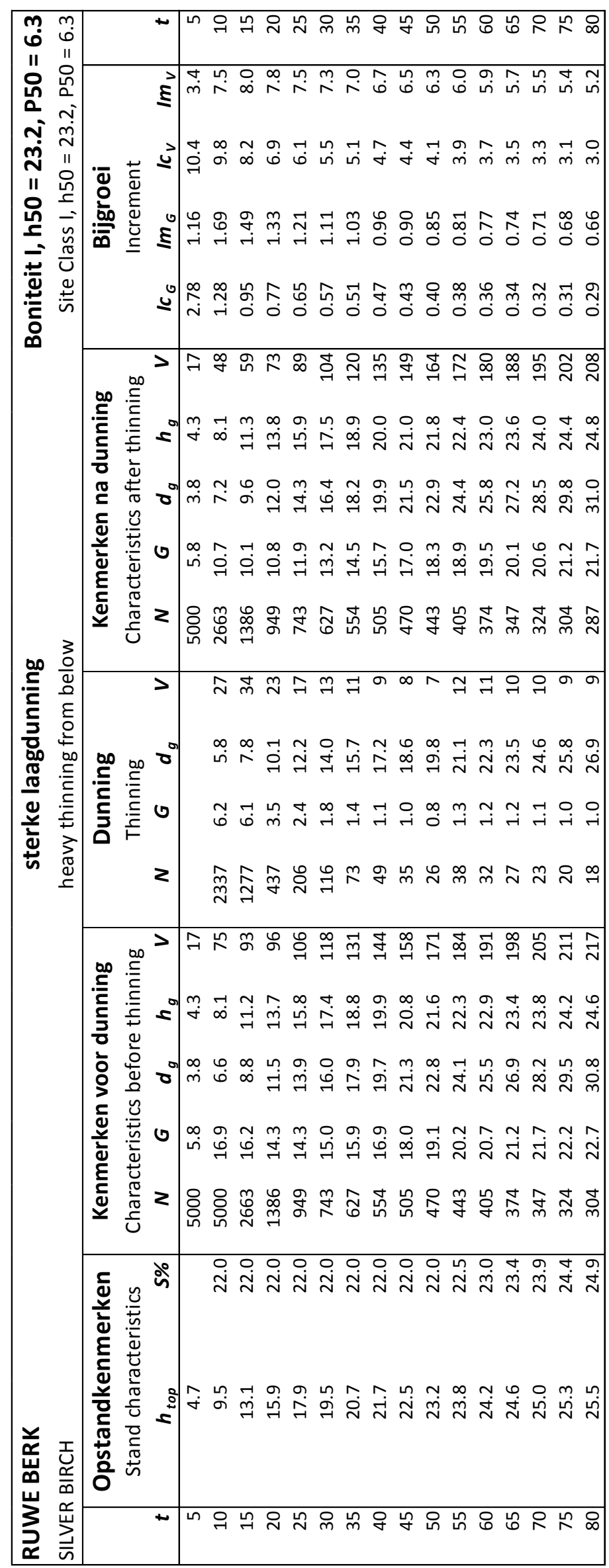




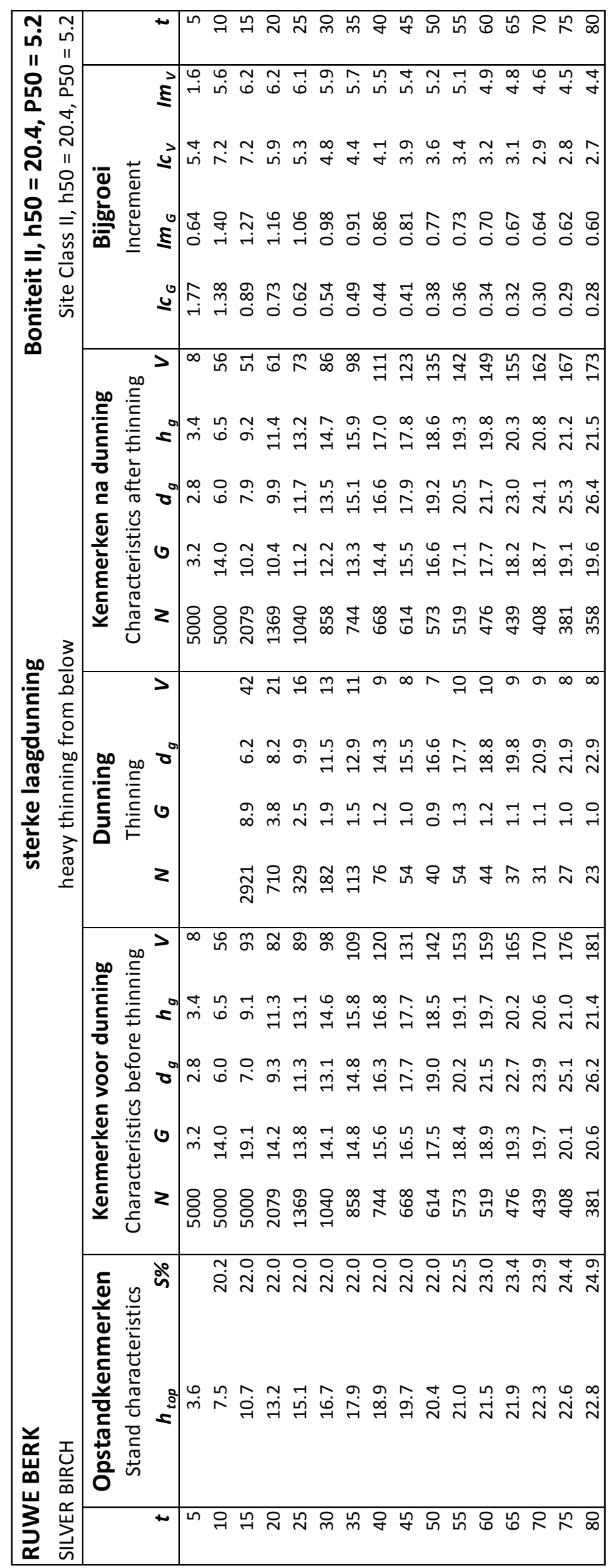




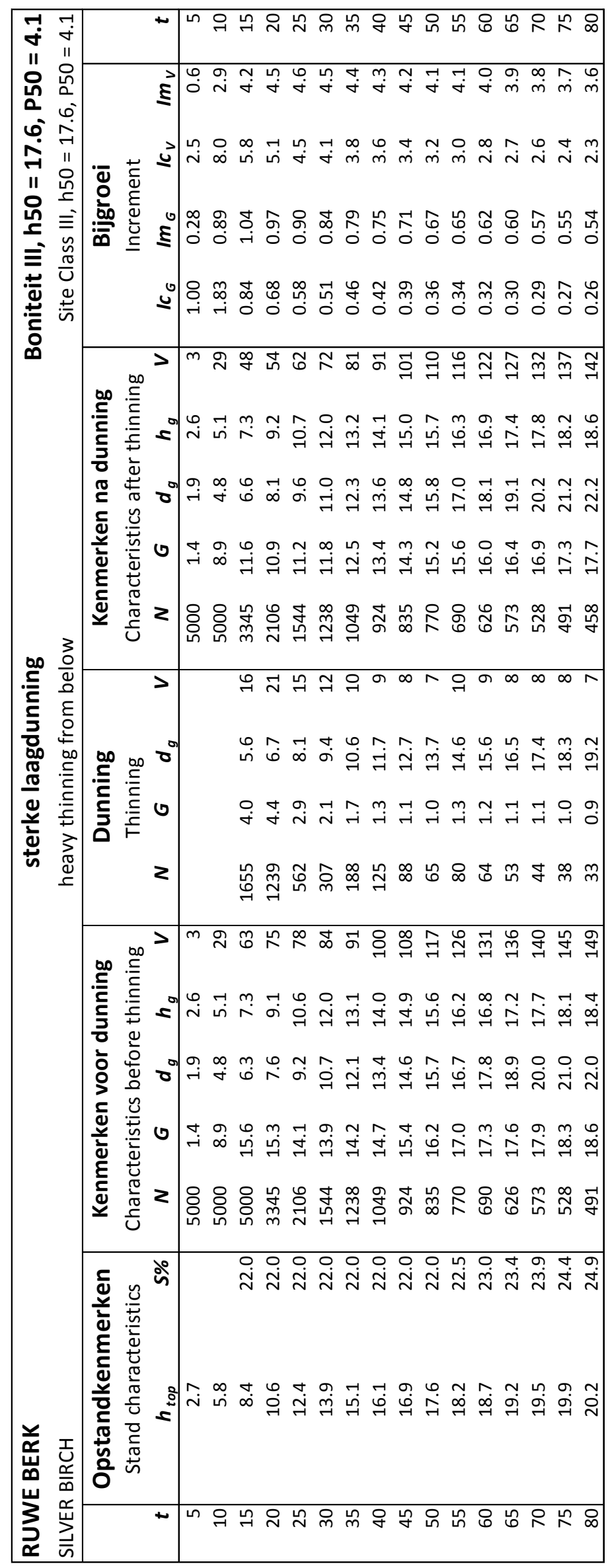




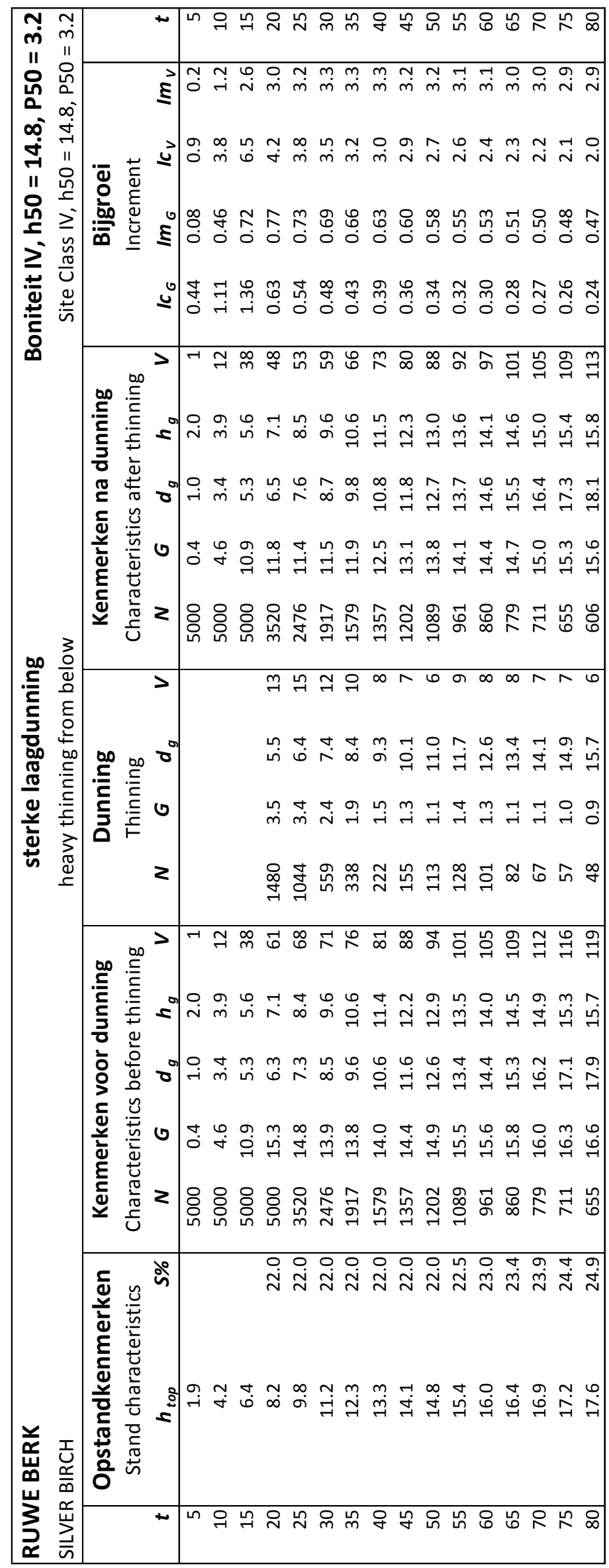




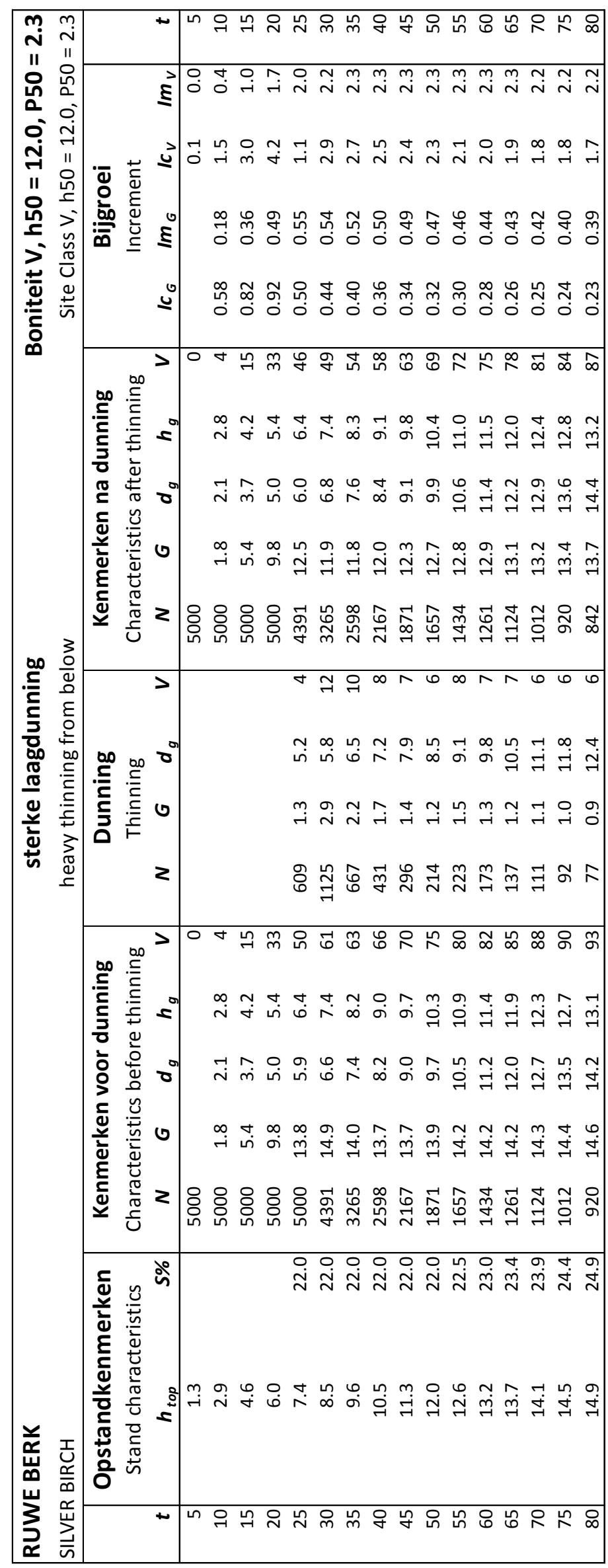

